\title{
Effect of Template Type on the Trametes versicolor Laccase- Catalyzed Oligomerization of the Aniline Dimer p-Aminodiphenylamine (PADPA)
}

\author{
Keita Kashima, ${ }^{\dagger \dagger}$ Tomoyuki Fujisaki, ${ }^{\dagger \neq}$ Sandra Serrano-Luginbühl, ${ }^{\dagger}$ Reinhard Kissner, ${ }^{\S}$
} Aleksandra Janošević Ležaic,, $\|$ Danica Bajuk-Bogdanović, ${ }^{\perp}$ Gordana Ćirić-Marjanović, ${ }^{\perp}$ Stephan Busato, ${ }^{\dagger}$ Takashi Ishikawa, ${ }^{\#}$ and Peter Walde ${ }^{* \dagger} \dagger$

${ }^{\dagger}$ Department of Materials, ETH Zürich, Vladimir-Prelog-Weg 5, 8093 Zürich, Switzerland

${ }^{*}$ Department of Materials Chemistry and Bioengineering, National Institute of Technology, Oyama College, 771 Nakakuki, Oyama, Tochigi 323-0806, Japan

${ }^{\S}$ Department of Chemistry and Applied Biosciences, ETH Zürich, Vladimir-Prelog-Weg 3, 8093 Zürich, Switzerland

"Faculty of Pharmacy, University of Belgrade, Vojvode Stepe Street 450, 11221 Belgrade, Serbia

${ }^{\perp}$ Faculty of Physical Chemistry, University of Belgrade, Studentski trg 12-16, 11158 Belgrade, Serbia

\# Department of Biology and Chemistry, Paul Scherrer Institute (PSI), CH-5231 Villigen, Switzerland

Supporting Information

ABSTRACT: Many previous studies have shown that (i) the oxidation of aniline or the aniline dimer $p$-aminodiphenylamine (PADPA) in a slightly acidic aqueous solution can be catalyzed with heme peroxidases or multicopper laccases and that (ii) subsequent reactions lead to oligomeric or polymeric products, which resemble chemically synthesized polyaniline in its conductive emeraldine salt form (PANI-ES), provided that (iii) an anionic "template" is present in the reaction medium. Good templates are anionic polyelectrolytes, micelles, or vesicles. Under optimal conditions, their presence directs the reactions in a positive way toward the desired formation of PANI-ES-type products. The effect of four different types of anionic templates on the formation of PANI-

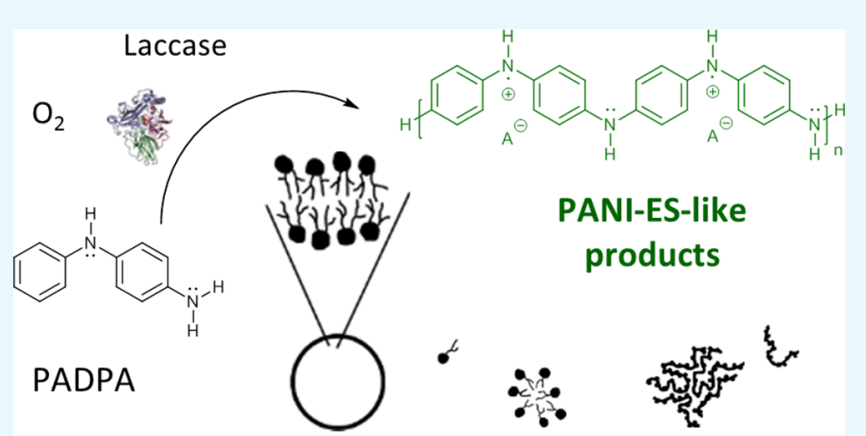

Sulfonated Vesicles, Micelles or Polyelectrolyte as template ES-like products from PADPA was investigated and compared by using Trametes versicolor laccase (TvL) as a catalyst in an aqueous $\mathrm{pH} 3.5$ solution at room temperature. All four templates contain sulfonate groups: the sodium salt of the polyelectrolyte sulfonated polystyrene (SPS), micelles from sodium dodecylbenzenesulfonate (SDBS), vesicles from a 1:1 molar mixture of SDBS and decanoic acid, and vesicles from sodium bis(2-ethylhexyl)sulfosuccinate (AOT). Although with all four templates, stable, inkjet-printable solutions or suspensions consisting of PANI-ES-type products were obtained under optimized conditions, considerably higher amounts of TvL were required with SDBS micelles to achieve comparable monomer conversion to PANI-ES-like products during the same time period when compared to those with SPS or the two types of vesicles. This makes SDBS micelles less attractive as templates for the investigated reaction. In situ UV/vis/near-infrared, electron paramagnetic resonance (EPR), and Raman spectroscopy measurements in combination with an high-performance liquid chromatography analysis of extracted reaction products, which were deprotonated and chemically reduced, showed seemingly small but significant differences in the composition of the mixtures obtained when reaching reaction equilibrium after $24 \mathrm{~h}$. With the two vesicle systems, the content of unwanted substituted phenazine units was lower than in the case of SPS polyelectrolyte and SDBS micelles. The EPR spectra indicate a more localized, narrower distribution of electronic states of the paramagnetic centers of the PANI-ES-type products synthesized in the presence of the two vesicle systems when compared to that of the similar products obtained with the SPS polyelectrolyte and SDBS micelles as templates. Overall, the data obtained from the different complementary methods indicate that with the two vesicle systems structurally more uniform (regular) PANI-ES-type products formed. Among the two investigated vesicle systems, for the investigated reaction (oxidation of PADPA with $\mathrm{TvL}$ and $\mathrm{O}_{2}$ ), AOT appears a somewhat better choice as it leads to a higher content of the PANI-ES polaron form.

\section{INTRODUCTION}

The efficient and environmentally friendly enzymatic synthesis of polyaniline products in their conductive emeraldine salt
Received: December 7, 2018

Accepted: January 21, 2019

Published: February 8, 2019 
form (PANI-ES) has been a scientific challenge for many research groups during the last years. ${ }^{1-29}$ The reasons for this are the many possible applications of conductive polyaniline, ${ }^{30-34}$ even for biomedical applications (for example, in tissue engineering). ${ }^{35,36}$ Due to the polymeric nature of PANIES products and their insolubility in common solvents, ${ }^{37}$ independent of whether they are obtained through electrochemical, $^{33}$ chemical, $^{33,38}$ enzymatic, or enzyme-mimicking ${ }^{39,40}$ routes, the analysis of the chemical structure of PANI-ES-type products is often difficult or impossible. By using $p$-aminodiphenylamine (PADPA) instead of aniline, the situation in terms of product analysis is much better. ${ }^{19,21-23}$

Based on our previous detailed investigations of the Trametes versicolor laccase $(\mathrm{TvL}) / \mathrm{O}_{2}$-catalyzed oxidative oligomerization of PADPA (Scheme 1) in the presence of $100 \mathrm{~nm}$ sized vesicles from sodium bis(2-ethylhexyl)sulfosuccinate (AOT, Chart 1) as "templates" at $\mathrm{pH} 3.5$ (0.1 $\left.\mathrm{M} \mathrm{NaH} \mathrm{PO}_{4}\right),{ }^{19-22}$ we questioned whether other templates with sulfonate groups can also be used successfully for the same reaction, and if yes, how the outcome of the reaction compares with the one using AOT vesicles. By the term

Scheme 1. Reaction Scheme for the Oxidation and Oligomerization of the Aniline Dimer $p$-Aminodiphenylamine (PADPA) with $T$. versicolor Laccase ( TvL)/ $\mathrm{O}_{2}$ into Products That Consist of Tetraaniline Repeating Units in a Polaron or Bipolaron (Dication) State, ${ }^{19}$ the Smallest Units of the Ideal Emeraldine Salt Form of Polyaniline $(\text { PANI-ES })^{54, a}$

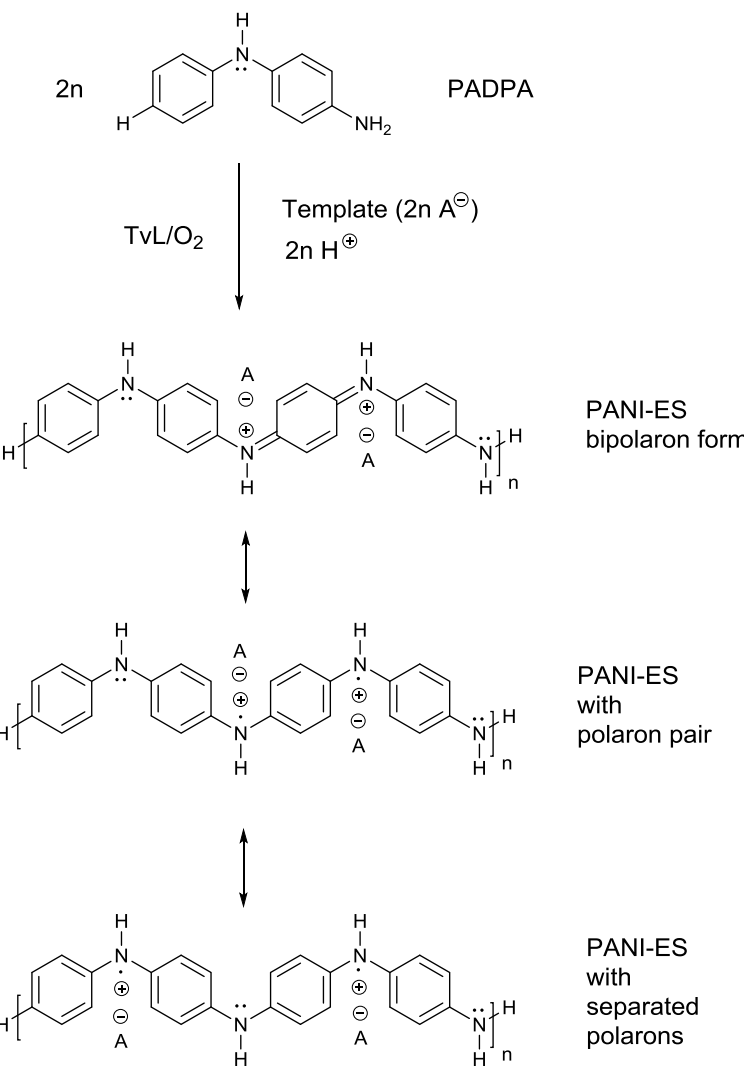

${ }^{a}$ The polaron state is shown as a diradical dication form with either polaron pairs or with separated, delocalized polarons (two semiquinone radical cations). The templates, consisting of anionic groups $\mathrm{A}^{-}$, promote the formation of PANI-ES.
Chart 1. Chemical Structures of Sodium Bis(2ethylhexyl)sulfosuccinate (AOT), "Sodium Dodecylbenzenesulfonate" (SDBS, a Mixture of Different Isomers), ${ }^{13,62,63}$ Decanoic Acid (DA), and Sulfonated Polystyrene (SPS, as Sodium Salt, Assuming a Sulfonation Level of $100 \%$; $^{64-66} M_{\mathrm{w}}=70000 \mathrm{Da}, n \approx 330$ )
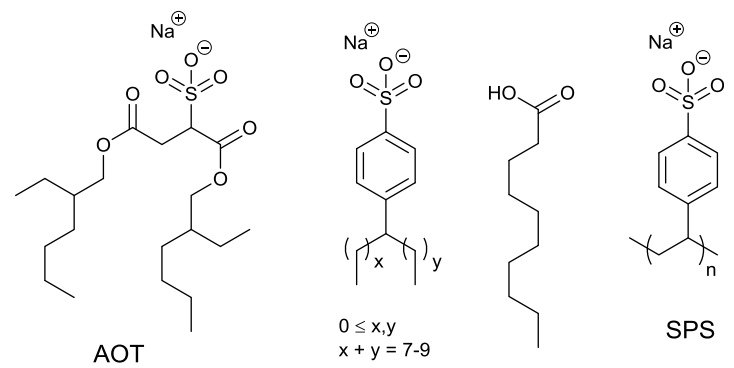

SDBS

DA

"template", we mean an additive that has a desired influence on the outcome of a chemical or enzymatic reaction in terms of chemical structure so that the structure is "dictated" by the template molecules. ${ }^{15,41-53}$ For the particular case investigated, the desired reaction products should resemble PANI-ES (Scheme 1). ${ }^{19,54}$ The templates chosen for the comparison with AOT vesicles were vesicles formed from a $1: 1$ molar mixture of sodium dodecylbenzenesulfonate (SDBS) and decanoic acid (DA), SDBS micelles, and the sodium salt of the polyelectrolyte sulfonated polystyrene (often abbreviated as SPS). For the chemical structures of the template-forming molecules, see Chart 1 . SDBS micelles were already applied for the Trametes hirsuta laccase $/ \mathrm{O}_{2}$-catalyzed oligomerization of PADPA by Shumakovich et al., ${ }^{8}$ and all four templates were previously used for the enzymatic polymerization of aniline: SPS polyelectrolyte, ${ }^{1-3}$ SDBS micelles, ${ }^{3,4,6,27}$ SDBS/DA (1:1) vesicles, ${ }^{13}$ and AOT vesicles. ${ }^{14,16,17}$ In all of these previous cases, the aim was to obtain products with spectroscopic properties that are characteristic for the linear conductive form of PANI-ES: (i) they must have a green color with high absorption in the near-infrared (NIR) region, at about 800$1000 \mathrm{~nm}$ or above, and they must have an absorption band at about $420 \mathrm{~nm}$ due to the formation of polarons (radical cations) for which the templates act as counter ions (dopants); ${ }^{33,55-58}$ (ii) they must have a low absorption at about 500-600 nm since this is indicative of a low extent of branching ${ }^{2}$ or undesired phenazine-type structural unit formation; ${ }^{23}$ (iii) they must have characteristic Raman bands originating from $\mathrm{C}-\mathrm{N}^{\bullet+}$ stretching vibrations of polaronic structures (at about $1320-1380 \mathrm{~cm}^{-1}$ ); ${ }^{20,22,33,59}$ and (iv) they must be paramagnetic due to the polarons, i.e., an electron paramagnetic resonance (EPR) spectrum should be measurable. $^{18,58,60,61}$

In a previous investigation by Liu et al., ${ }^{3}$ the effect of different templates on the horseradish peroxidase $/ \mathrm{H}_{2} \mathrm{O}_{2}$ mediated polymerization of aniline was compared; it was found that the use of SDBS micelles or SPS polyelectrolyte was an improvement over cationic, nonionic, or other anionic templates (bearing carboxylate or phosphate groups). ${ }^{3} \mathrm{We}$ now report about a comparison of template effects on a related enzymatic reaction, the $\mathrm{TvL} / \mathrm{O}_{2}$-mediated oligomerization of the aniline dimer PADPA, by using different sulfonate-groupbearing templates only. The focus was set on a comparison of the template type, i.e., polyelectrolyte versus micelles versus 
vesicles. To the best of our knowledge, this is the first systematic approach for such comparison, although Zhang et al. $^{29}$ already reported about a comparison of the Aspergillus laccase $/ \mathrm{O}_{2}$-mediated polymerization of aniline in the presence of a micellar template (SDBS) or of a polyelectrolyte (ligninosulfonate). The use of ligninosulfonate was shown to have advantages over SDBS micelles. ${ }^{29}$ Furthermore, de Salas et al. ${ }^{27}$ used a high-potential laccase engineered and expressed in Saccharomyces cerevisiae for the oxidative polymerization of aniline in the presence of an anionic template (either AOT vesicles, SDBS micelles, or sodium lauryl ether sulfate micelles); SDBS micelles were found to be superior. ${ }^{27}$

The use of PADPA as a monomer instead of aniline has both benefits and drawbacks. The main reaction products are PADPA oligomers only, ${ }^{19,21,22}$ which is a disadvantage if one aims at synthesizing polymeric molecules. However, at the same time, it is also an advantage since PADPA oligomers (in their neutral form) can be extracted from the reaction mixture into an organic solvent, separated chromatographically, and then analyzed by mass spectrometry (MS)..$^{19,21,22}$ With such analysis, it could be shown that the presence of AOT vesicles in the case of the $\mathrm{TvL} / \mathrm{O}_{2}$-catalyzed oligomerization of PADPA completely suppresses the formation of undesired side products that contain oxygen atoms (which originate from the hydrolysis of reaction intermediates if AOT vesicles are absent). ${ }^{21}$

Our aim of comparing the effects of different types of templates on the $\mathrm{TvL} / \mathrm{O}_{2}$-catalyzed oligomerization of PADPA is apparently an experimentally simple task. However, the choice of conditions under which the comparison should actually be made is not straightforward. It would be too simple, for example, to compare the AOT vesicle template system with the SDBS micelle system using identical amphiphile concentrations in both cases. AOT in $0.1 \mathrm{M} \mathrm{NaH}_{2} \mathrm{PO}_{4}$ solution at $\mathrm{pH}$ 3.5 , the optimal reaction conditions, forms bilayered vesicles at a critical concentration for vesicle formation ( $\mathrm{cvc}$ ) of about 0.4 $\mathrm{mM} .{ }^{14,67}$ On the other hand, SDBS in the same aqueous solution forms micelles at a critical concentration for micelle formation $(\mathrm{cmc})$ that may be different from the cvc of AOT vesicles; vesicles and micelles are different types of polymolecular assemblies. Literature values for the $\mathrm{cmc}$ value

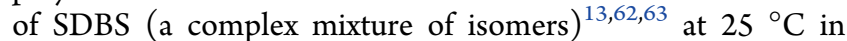
water are $3.1,{ }^{68} 2.7-2.9,{ }^{62} 1.4-1.9,,^{69,70}$ or $1.2 \mathrm{mM}^{71}$ Although the values deviate, possibly due to the different sources of SDBS and the method of $\mathrm{cmc}$ determination, the $\mathrm{cmc}$ value for SDBS in the $\mathrm{pH} 3.5$ solution used $\left(0.1 \mathrm{M} \mathrm{NaH}_{2} \mathrm{PO}_{4}\right)$ is expected to be lower than the $\mathrm{cmc}$ value determined in deionized water; ${ }^{72}$ see Section 3. SPS, for which we assume that it is sulfonated in each repeating unit, ${ }^{64-66}$ is a macromolecule and as such has not much in common with a vesicle. Based on these considerations, we decided to first optimize for each of the three new templates, SPS, SDBS micelles, and SDBS/DA (1:1) vesicles, the reaction conditions but keeping (i) the aqueous solution the same, $0.1 \mathrm{M}$ $\mathrm{NaH}_{2} \mathrm{PO}_{4}\left(\mathrm{pH}=3.5\right.$, prepared from $\mathrm{NaH}_{2} \mathrm{PO}_{4}$ and phosphoric acid), ${ }^{22}$ (ii) the PADPA concentration the same $(1.0 \mathrm{mM})$, and (iii) the TvL concentration the same $(2.6 \mathrm{nM})$. These are the conditions that we found to be ideal for a reproducible reaction with $100 \mathrm{~nm}$ sized AOT vesicles at an AOT concentration of $1.5 \mathrm{mM}^{22}$

The reaction optimizations for SDBS/DA (1:1) vesicles, SDBS micelles, and the SPS polyelectrolyte were carried out on the basis of the following criteria (see also above). First, there should be no product precipitation during and after the reaction, i.e., a stable solution or suspension should result from the reaction. Second, the products should have a high absorbance at $\approx 1000 \mathrm{~nm}\left(A_{\approx 1000}\right)$, a band at $\approx 420 \mathrm{~nm}$, and a low absorbance at $\approx 500 \mathrm{~nm}\left(A_{\approx 500}\right)$. The reaction optimization was performed by systematic UV/vis/NIR absorption measurements and visual inspections (detection of precipitation). After identification of the conditions we considered optimal for each template, direct comparisons were made not only by detailed in situ UV/vis/NIR measurements but also by in situ EPR and in situ Raman spectroscopy measurements, as well as by an high-performance liquid chromatography (HPLC)-MS analysis of the extracted, deprotonated, and chemically reduced reaction products, and by tests of the inkjet-printability of the as-obtained reaction solutions or suspensions. The aim of the HPLC-MS analysis was to obtain comparative information about the PADPA conversion and the product distribution.

\section{MATERIALS AND METHODS}

2.1. Materials. Laccase from $T$. versicolor ( TvL, EC 1.10.3.2; product no. 51639, $13.6 \mathrm{U} \mathrm{mg}^{-1}$, lot no. BCBF7247 V), docusate sodium salt (AOT, bis(2-ethylhexyl)sulfosuccinate sodium salt, BioUltra, $\geq 99.0 \%$ ), poly(sodium 4styrenesulfonate) (SPS, average $M_{\mathrm{w}}=70000 \mathrm{Da}$ ), 2,2' -azinobis(3-ethylbenzothiazoline-6-sulfonic acid)diammonium salt (ABTS $\left(\mathrm{NH}_{4}\right)_{2}, \geq 98 \%$ ), sodium phosphate monobasic $\left(\mathrm{NaH}_{2} \mathrm{PO}_{4}, \geq 99.0 \%\right.$ ), acetonitrile (for HPLC or for UV spectroscopy, $\geq 99.9 \%$ ), hydrazine hydrate $(50-60 \%)$, and pinacyanol chloride were purchased from Sigma-Aldrich. Decanoic acid (DA, $\geq 99 \%)$, ethanol (99.99\%), orthophosphoric acid $\left(\mathrm{H}_{3} \mathrm{PO}_{4}, 85 \%\right)$, and tert-butyl methyl ether (MTBE, $\geq 99.0 \%$ ) were purchased from Fluka. Ammonia solution (25\%) was purchased from Merck. Dodecylbenzensulfonic acid sodium salt (SDBS, hard type, >95\%) was purchased from TCI Europe. Dichloromethane (99.5\%) was purchased from J.T. Baker. N-Phenyl-p-phenylenediamine ( $p$ aminodiphenylamine, PADPA, 98\%) was from either SigmaAldrich or abcr $\mathrm{GmbH}$, purified by recrystallization from hexane, four to five times until white crystals were obtained. All other chemicals were used as obtained.

2.2. Preparation of $\mathrm{pH} 3.5$ Phosphate Solution and PADPA Stock Solution. A pH 3.5 phosphate solution (0.1 $\mathrm{M})$ was prepared at room temperature (RT) by first dissolving $0.1 \mathrm{~mol}$ of $\mathrm{NaH}_{2} \mathrm{PO}_{4}$ in deionized water to yield a total volume of $1 \mathrm{~L}$, followed by adjustment of the $\mathrm{pH}$ value with $1 \mathrm{M}$ $\mathrm{H}_{3} \mathrm{PO}_{4}$ (and not $\mathrm{HCl}$ ) ${ }^{22}$ until $\mathrm{pH}$ 3.5. This solution is called "pH 3.5 solution". A stock solution of $0.15 \mathrm{M}$ PADPA in ethanol was prepared by dissolving $13.8 \mathrm{mg}$ of PADPA in 500 $\mu \mathrm{L}$ of ethanol. This solution was stored in a refrigerator at $T \approx$ $7{ }^{\circ} \mathrm{C}$ and used within 1 day.

2.3. Preparation of AOT Vesicles. Vesicle suspensions of $20 \mathrm{mM}$ AOT, consisting of mainly unilamellar vesicles with an average diameter of about $100 \mathrm{~nm}$, were prepared with the freeze-thaw/extrusion method, as described before. ${ }^{14,16,21}$ The amount of $0.178 \mathrm{~g}$ of AOT $(0.4 \mathrm{mmol})$ was dissolved in about $5 \mathrm{~mL}$ of chloroform. This AOT solution was added to a $250 \mathrm{~mL}$ round-bottom glass flask, and the solvent was removed by rotary evaporation to form a thin AOT film, followed by high vacuum drying overnight. The dry AOT film was then hydrated by slowly vortexing at RT with $20 \mathrm{~mL}$ of the $\mathrm{pH} 3.5$ solution. The obtained AOT vesicle suspension was frozen by placing the round-bottom flask into liquid nitrogen 
and then thawed in a water bath heated to $60{ }^{\circ} \mathrm{C}$. This freezing-thawing process was repeated 10 times. Afterward, the suspension was extruded five times through a $200 \mathrm{~nm}$ Nuclepore polycarbonate membrane and then 10 times through a $100 \mathrm{~nm}$ membrane using the Extruder from Lipex Biomembranes (Vancouver, Canada). ${ }^{73}$ The thus-prepared vesicle suspensions were stored at $\mathrm{RT}$ and used within 3 weeks $\left([\mathrm{AOT}]=20 \mathrm{mM},\left[\mathrm{NaH}_{2} \mathrm{PO}_{4}\right]+\left[\mathrm{H}_{3} \mathrm{PO}_{4}\right]=0.1 \mathrm{M}, \mathrm{pH}=\right.$ 3.5).

2.4. Preparation of SDBS/Decanoic Acid (1:1) Vesicles. Vesicle suspensions of equimolar amounts of SDBS and decanoic acid (DA) were prepared with the freezing-thawing/extrusion method as described before. ${ }^{13}$ The amounts of $0.1394 \mathrm{~g}$ of SDBS $(0.4 \mathrm{mmol})$ and $0.0689 \mathrm{~g}$ of DA $(0.4 \mathrm{mmol})$ were dissolved in about $5 \mathrm{~mL}$ of chloroform and added to a $250 \mathrm{~mL}$ round-bottom glass flask. The next steps were the same as described for the preparation of AOT vesicles. The resulting SDBS/DA (1:1) vesicle suspension was stored at RT and used within 3 weeks $([\mathrm{SDBS}]=[\mathrm{DA}]=20$ $\left.\mathrm{mM},\left[\mathrm{NaH}_{2} \mathrm{PO}_{4}\right]+\left[\mathrm{H}_{3} \mathrm{PO}_{4}\right]=0.1 \mathrm{M}, \mathrm{pH}=3.5\right)$.

2.5. Preparation of SDBS Micelles. A $20 \mathrm{mM}$ SDBS micellar solution was prepared at RT by dissolving $0.1394 \mathrm{~g}$ $(0.4 \mathrm{mmol})$ of SDBS in $20 \mathrm{~mL}$ of $\mathrm{pH}=3.5$ solution. The micellar solution was stored at RT and used within 1 month $\left([\mathrm{SDBS}]=20 \mathrm{mM},\left[\mathrm{NaH}_{2} \mathrm{PO}_{4}\right]+\left[\mathrm{H}_{3} \mathrm{PO}_{4}\right]=0.1 \mathrm{M}, \mathrm{pH}=\right.$ $3.5)$.

The critical concentration for SDBS micelle formation (cmc) was determined in the same way as described before. ${ }^{74}$ A methanolic stock solution of pinacyanol chloride was first prepared by dissolving $1.36 \mathrm{mg}$ of pinacyanol chloride ( 3.5 $\mu \mathrm{mol})$ in $10 \mathrm{~mL}$ of methanol. A volume of $5 \mu \mathrm{L}$ of this stock solution was added to $0.6 \mathrm{~mL}$ of SDBS solution of defined concentration (prepared in $\mathrm{pH} 3.5$ solution), and the absorbance at $606 \mathrm{~nm}\left(A_{606}\right)$ was measured with a Jasco V$670 \mathrm{UV} /$ vis/NIR spectrophotometer using a $1.0 \mathrm{~cm}$ quartz cuvette ([pinacyanol chloride] $=2.9 \mu \mathrm{M})$. From a plot of $A_{606}$ versus molar SDBS concentration, the $\mathrm{cmc}$ value was taken as the SDBS concentration at which the value of $A_{606}$ started to increase.

2.6. Preparation of SPS Polyelectrolyte Solution. SPS was dissolved in the $\mathrm{pH} 3.5$ solution at $0.08248 \mathrm{~g}$ per $20 \mathrm{~mL}$ of the $\mathrm{pH} 3.5$ solution. The concentration of SPS repeating units, [SPS r.u.], was calculated by taking into account the molar mass of the r.u., $\mathrm{M}\left(\mathrm{NaC}_{8} \mathrm{H}_{7} \mathrm{SO}_{3}\right)=206.19 \mathrm{~g} \mathrm{~mol}^{-1}$. This polyelectrolyte solution was stored at $\mathrm{RT}$ and used within 1 month ([SPS r.u. $]=20 \mathrm{mM},\left[\mathrm{NaH}_{2} \mathrm{PO}_{4}\right]+\left[\mathrm{H}_{3} \mathrm{PO}_{4}\right]=0.1 \mathrm{M}$, $\mathrm{pH}=3.5)$.

2.7. Dynamic Light Scattering (DLS) and Cryogenic Transmission Electron Microscopy (Cryo-TEM) Measurements. Dynamic light scattering (DLS) measurements were carried out with Malvern Zetasizer Nano and disposable polystyrene microcuvettes $(40 \mu \mathrm{L})$. The cryogenic transmission electron microscopy (cryo-TEM) analysis was performed in the same way as described before. ${ }^{75}$

2.8. Preparation of Laccase Stock Solution. A laccase stock solution was prepared as follows. ${ }^{22}$ The amount of 12.92 $\mathrm{mg}$ of laccase (TvL) powder was first added to a $1.5 \mathrm{~mL}$ polypropylene Eppendorf tube. Afterward, $1.0 \mathrm{~mL}$ deionized water was added and the tube was slowly agitated. The solution was centrifuged with Eppendorf centrifuge $5415 \mathrm{D}$ (6000 rpm, $2 \mathrm{~min}$ ). Afterward, the supernatant solution was diluted 1:9 (v/v) with deionized water and the molar concentration of active TvL was estimated as described before. ${ }^{19}$ This diluted solution yielded $[\mathrm{TvL}] \approx 1.6 \mu \mathrm{M}$ and was kept in the refrigerator at $T \approx 7{ }^{\circ} \mathrm{C}$ and used within 1 week.

2.9. Laccase Activity and Stability in the Presence of Templates. The activity of TvL was measured spectrophotometrically with $0.25 \mathrm{mM} \mathrm{ABTS}^{2-}$ as the substrate in the $\mathrm{pH} 3.5$ solution at RT, as described before. ${ }^{19}$ A Cary $1 \mathrm{E}$ spectrophotometer (from Varian) and $1.5 \mathrm{~mL}$ quartz cuvettes with a path length of $1 \mathrm{~cm}$ were used. The assay solution was prepared by first adding $935 \mu \mathrm{L}$ of a $\mathrm{pH} 3.5$ solution to the cuvette. Afterward, $50 \mu \mathrm{L}$ of an ABTS $^{2-}$ stock solution $(5 \mathrm{mM}$ in $\mathrm{pH}$ 3.5 solution) was added, finally followed by $15 \mu \mathrm{L}$ of a TvL solution containing a defined amount of one of the templates, stored for a desired period of time $(2.6 \mathrm{nM}$ TvL). After gentle mixing, the solution was incubated for $(t) 7 \mathrm{~min}$ and the increase of $A_{414}$, originating from the formation of $\mathrm{ABTS}^{\bullet-}$, was measured for $3 \mathrm{~min}$ at $\mathrm{RT}$. The relative $\mathrm{TvL}$ activity is expressed as $\Delta A_{414} / \Delta t\left(\mathrm{~h}^{-1}\right)$.

2.10. Reaction Mixtures. All reactions were carried out in volumes of $10 \mathrm{~mL}$ within $50 \mathrm{~mL}$ Schott glass bottles, closed with a screw cap. Defined volumes of the different separately prepared stock solutions were added in the following sequence: (a) pH 3.5 solution; (b) template stock solution; (c) PADPA stock solution; and (d) TvL stock solution. After mixing by gentle agitation (set to reaction time $t=0$ ), the reaction mixtures were left standing in the closed bottles at RT until the screw cap was removed for withdrawing a portion of the reaction mixtures for analysis by one of the methods. Details about the various volumes of the stock solutions used for the four different template systems (i-iv) are given in Table S-1 for each of the elaborated optimal conditions (always $[\mathrm{PADPA}]=1.0 \mathrm{mM}, \mathrm{pH}=3.5)\left(\left[\mathrm{NaH}_{2} \mathrm{PO}_{4}\right]+\left[\mathrm{H}_{3} \mathrm{PO}_{4}\right]=\right.$ $0.1 \mathrm{M}):(\mathrm{i})[\mathrm{AOT}]=1.5 \mathrm{mM},[\mathrm{TvL}]=2.6 \mathrm{nM}$; (ii) $[\mathrm{SDBS}]=$ $[\mathrm{DA}]=1.0 \mathrm{mM},[\mathrm{TvL}]=2.6 \mathrm{nM}$; (iii) $[\mathrm{SDBS}]=1.7 \mathrm{mM}$, $[\mathrm{TvL}]=2.6$ or $26 \mathrm{nM}$; (iv) [SPS r.u.] $=2.9 \mathrm{mM}$, [TvL] $=2.6$ nM.

2.11. UV/Vis/NIR Spectroscopy Measurements. In situ UV/vis/NIR spectroscopy measurements were carried out with a JASCO V-670 spectrophotometer. Volumes of $0.3 \mathrm{~mL}$ were withdrawn from the reaction mixtures at desired time points. The absorption spectrum was recorded from 1500 to $190 \mathrm{~nm}$ using quartz cuvettes (path length: $0.1 \mathrm{~cm}$, volume: 0.3 $\mathrm{mL})$.

2.12. EPR Spectroscopy Measurements. In situ EPR spectroscopy measurements were carried out with a Bruker EMX X-band spectrometer equipped with a TM cavity in the same way as described before. ${ }^{22}$

2.13. Raman Spectroscopy Measurements. In situ Raman spectroscopy measurements were carried out with a DXR Raman microscope (Thermo Scientific), equipped with a research optical microscope and a charge-coupled device detector. A $\mathrm{HeNe}$ gas laser was used with an excitation wavelength of $633 \mathrm{~nm}$, as described before. ${ }^{20,22}$ The Raman spectra of the reaction products were recorded from 2000 to $300 \mathrm{~cm}^{-1}$ without interrupting the ongoing reactions and without isolation of the reaction products, i.e., in situ, by withdrawing aliquots of $5 \mu \mathrm{L}$ volume from the same reaction mixture at specified reaction times and transferring them into sample wells at the sample slide (Gold EZ-Spot Micro Mount sample slide, from Thermo Scientific). Each spectrum was measured for a new aliquot taken from the reaction mixture at the specified time and transferred into the empty and clean sample well. The slide with the sample of the reaction mixtures 
was placed on an $X-Y$ motorized sample stage, and the laser beam was focused on the sample using an objective magnification of $10 \times$. The scattered light was analyzed by the spectrograph with a 600 lines $\mathrm{mm}^{-1}$ grating. The laser power on the sample was kept at $5.0 \mathrm{~mW}$ (when SDBS/DA (1:1) vesicles, SDBS micelles, and the SPS polyelectrolyte were used as templates) or $4.0 \mathrm{~mW}$ (in the case of AOT vesicles). The spectra were recorded using $10 \mathrm{~s}$ exposure time and 10 exposures per spectrum. All Raman spectra are shown after automated fluorescence correction performed by OMNIC software (Thermo Scientific).

2.14. HPLC Measurements. The ex situ HPLC analysis of the reaction products was carried in exactly the same way as described before. ${ }^{21,22}$

2.15. Test of Inkjet-Printability. The as-obtained reaction mixtures were tested for their inkjet-printability on ordinary white paper (XEROX Business, $80 \mathrm{~g} \mathrm{~m}^{-2}$ ) using a thermal desktop inkjet printer (Hewlett Packard Deskjet $980 \mathrm{cxi} ; 600 \times 600 \mathrm{dpi}$; DIN A4 format) in the same way as described before. ${ }^{17}$ Each pattern was overprinted for a total of eight passes at the same place to increase the amount of deposited reaction mixture.

\section{RESULTS AND DISCUSSION}

3.1. Characteristics of the Different Templates Used. Aqueous $\mathrm{pH} 3.5$ suspensions or solutions of the four templates used, extruded AOT or SDBS/DA (1:1) vesicles, SDBS micelles, and the polyelectrolyte SPS, were analyzed in terms of average size by dynamic light scattering (DLS) at room temperature (Figure 1A). As expected, ${ }^{13,14}$ the vesicles had sizes of about $100 \mathrm{~nm}$ (hydrodynamic diameter, $D_{\mathrm{h}}$ ), whereas the SDBS micelles were shown to be much smaller $\left(D_{\mathrm{h}} \approx 6\right.$ $\mathrm{nm})$. Cryogenic transmission electron microscopy (cryo-TEM) measurements confirmed the presence of vesicles in the two vesicle suspensions. The detected vesicles were spherical and mainly unilamellar with sizes in the expected range (Figure 1B,C). For the SDBS micelles and SPS polyelectrolyte samples, cryo-TEM did not show any features that could be assigned to micelles or polyelectrolytes (Figure S-1). The cvc values for the AOT vesicle system were determined previously under comparable conditions, $(\approx 0.4 \mathrm{mM}) ;^{14}$ for the SDBS/DA (1:1) vesicles, the cvc is expected to be similar. Determinations of the cmc value for SDBS micelles with pinacyanol chloride yielded $\approx 0.3 \mathrm{mM}$ (Figure $1 \mathrm{D}$ ).

The DLS analysis of the SPS solution gave an average value of the hydrodynamic diameter $\left(D_{\mathrm{h}}\right)$ of about $13 \mathrm{~nm}$ (Figure 1A). Although we did not further examine the state of SPS (average $M_{\mathrm{w}}=70000 \mathrm{Da}$ ) in the $\mathrm{pH} 3.5$ phosphate solution used, it is likely that SPS in aqueous salt solution "clusters dynamically" (meaning "temporal aggregate formation"). ${ }^{76-78}$ This is schematically shown in Figure 1E, where for the sake of completeness schematic representations of SDBS micelles, SDBS/DA (1:1) vesicles, and AOT vesicles are given. A common feature of all four templates is that they all are soft, dispersed interface-rich systems ${ }^{79}$ bearing negatively charged hydrophilic soluble sulfonate groups, which are exposed to the aqueous bulk solution.

3.2. Optimal Conditions for the Laccase $/ \mathrm{O}_{2}$-Catalyzed Oxidation of PADPA in the Presence of SDBS/DA (1:1) Vesicles, SDBS Micelles, or SPS Polyelectrolyte. As already pointed out in Section 1, in our previous report on the $\mathrm{TvL} / \mathrm{O}_{2}$-catalyzed oligomerization of PADPA in the presence of extruded AOT vesicles, the following initial
(A) DLS

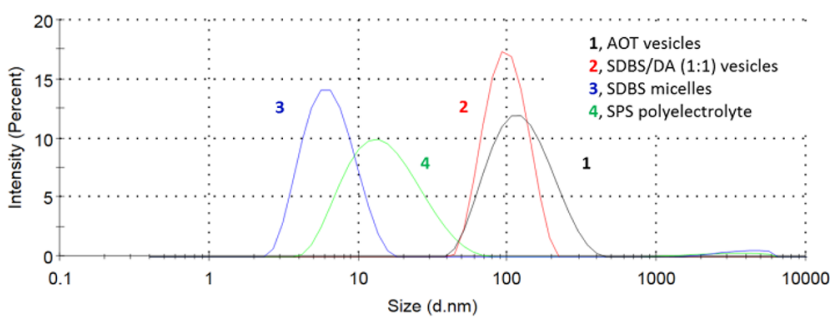

(B) Cryo-TEM: AOT vesicles

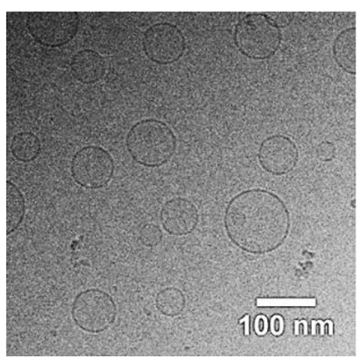

(C) Cryo-TEM: SDBS/DA (1:1) vesicles

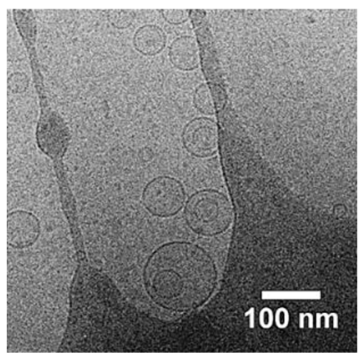

(D) Cmc determination: SDBS micelles

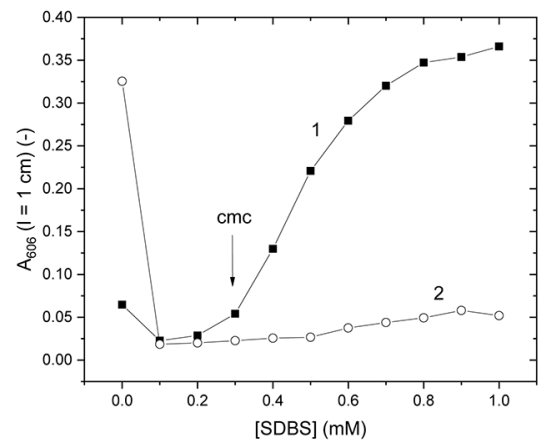

(E) The four templates used

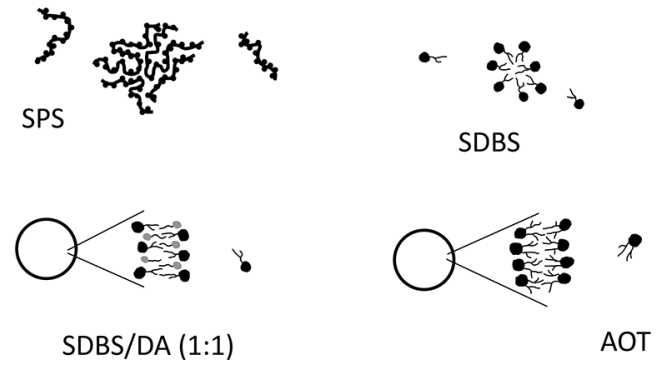

Figure 1. Characteristics of the four templates used $(\mathrm{pH}=3.5,0.1 \mathrm{M}$ $\mathrm{NaH}_{2} \mathrm{PO}_{4}, 25{ }^{\circ} \mathrm{C}$ ). (A) DLS analysis: mean diameters ( \pm standard deviations from the analysis of three samples each) were for the AOT vesicles, $110 \pm 3 \mathrm{~nm}(\mathrm{PDI}=0.19,20 \mathrm{mM}$ AOT), for the SDBS/DA $(1: 1)$ vesicles, $96 \pm 2 \mathrm{~nm}(\mathrm{PDI}=0.16,20 \mathrm{mM}$ SDBS, $20 \mathrm{mM} \mathrm{DA})$, for the SDBS micelles, $6.2 \pm 0.1 \mathrm{~nm}(\mathrm{PDI}=0.19,20 \mathrm{mM}$ SDBS $)$, and 
Figure 1. continued

for the SPS polyelectrolyte, $13.1 \pm 0.2 \mathrm{~nm}$ (PDI $=0.24,20 \mathrm{mM}$ repeating units). Note that the value for SPS has to be taken with caution since it is likely that nonspherical clusters form, which would require a more extensive DLS analysis for meaningful values of the size. $^{76}$ PDI means polydispersity index. (B, C) Cryo-TEM analysis of the AOT vesicles (10 mM AOT) and of the SDBS/DA (1:1) vesicles (10 mM SDBS, $10 \mathrm{mM} \mathrm{DA}$ ), respectively. (D) Determination of the cmc of SDBS with pinacyanol chloride $(2.9 \mu \mathrm{M})$ in the $\mathrm{pH} 3.5$ solution $(\square)$, yielding a value of $\approx 0.3 \mathrm{mM}$. For comparison, measurements were also made for SDBS dissolved in deionized water $(\mathrm{O})$, indicating that $\mathrm{cmc}$ (SDBS) in water is greater than 1.0 $\mathrm{mM}^{62,68-70}$ (E) Schematic representation of the likely state of the four templates at the conditions used for the enzymatic reaction investigated: SPS (as dynamic clusters of SPS chains), ${ }^{76-78}$ SDBS micelles, SDBS/DA (1:1) vesicles, and AOT vesicles.

conditions were shown to be optimal: $1.5 \mathrm{mM}$ AOT, $1.0 \mathrm{mM}$ PADPA, $2.6 \mathrm{nM}$ TvL, $\mathrm{pH}=3.5\left(0.1 \mathrm{M} \mathrm{NaH}_{2} \mathrm{PO}_{4} / \mathrm{H}_{3} \mathrm{PO}_{4}\right.$, no chloride ions), $t=24 \mathrm{~h}$, and $T \approx 25{ }^{\circ} \mathrm{C}$ (RT). ${ }^{22}$ For a comparison with the other three templates, SDBS/DA $(1: 1)$ vesicles, SDBS micelles, and SPS polyelectrolyte, we decided to keep the phosphate solution $\left(\mathrm{pH}=3.5,0.1 \mathrm{M} \mathrm{NaH}_{2} \mathrm{PO}_{4} /\right.$ $\mathrm{H}_{3} \mathrm{PO}_{4}$, chloride free), the PADPA concentration (1.0 mM), and also the TvL concentration $(2.6 \mathrm{nM})$ the same. Furthermore, we aimed to reach reaction equilibrium after $t$ $\leq 24 \mathrm{~h}$ at a reaction temperature of $T \approx 25{ }^{\circ} \mathrm{C}(\mathrm{RT})$. We then searched for the optimal conditions by varying the template molecule concentrations and applying the same criteria as in our previous work with AOT vesicles; ${ }^{22}$ see Section 1: (i) high absorption at $\lambda \approx 1000 \mathrm{~nm}\left(A_{1000}\right)$ after $t=24 \mathrm{~h}$ with a high $A_{\approx 1000} / A_{\approx 500}$ ratio, both indicative of the formation of products with a high content of linear PANI-ES repeating units (as the band at around $500 \mathrm{~nm}$ is typical for the formation of undesired substituted phenazine-type structures, ${ }^{22,23}$ whereas the band at around $1000 \mathrm{~nm}$ is due to ordinary PANI-ES structures $)^{33,55-58}$ and (ii) no precipitation during and at the end of the reaction. With this concept, the following conditions were found to be optimal for the three "new" templates.

(a) For SDBS/DA $(1: 1)$ vesicles: $[\mathrm{SDBS}]=[\mathrm{DA}]=1.0$ $\mathrm{mM}$, with characteristic absorption maxima at $\lambda \approx 1100$ and $440 \mathrm{~nm}$. For $[\mathrm{SDBS}]=[\mathrm{DA}]<0.9 \mathrm{mM}$, precipitation occurred, and for $[\mathrm{SDBS}]=[\mathrm{DA}]>1.0$
(A) AOT vesicles

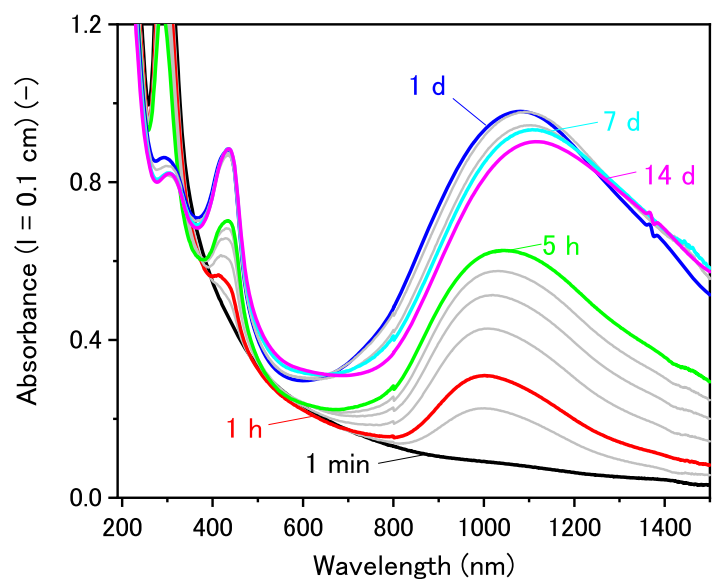

(C) SDBS micelles

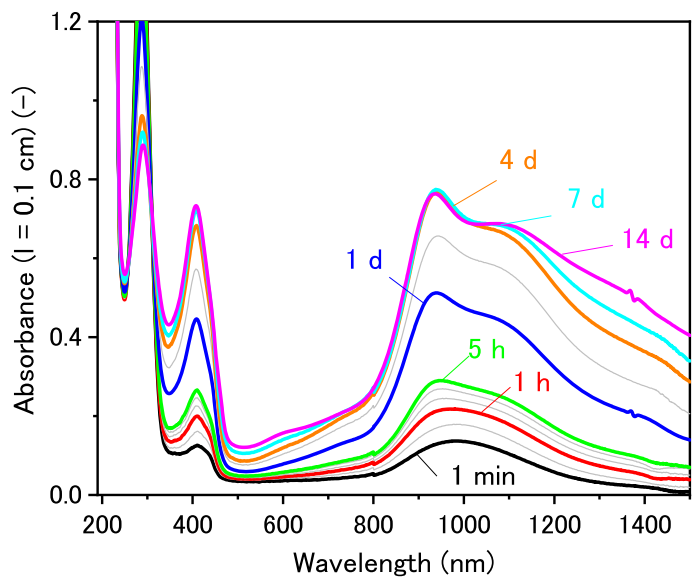

(B) SDBS/DA (1:1) vesicles

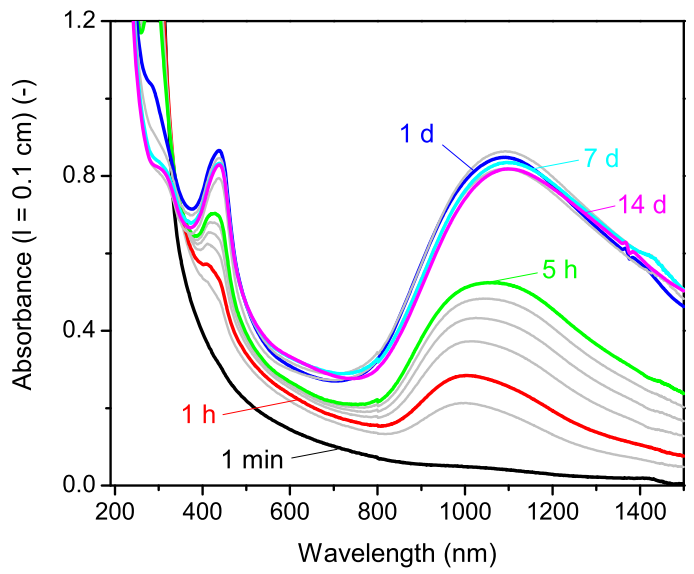

(D) SPS polyelectrolyte

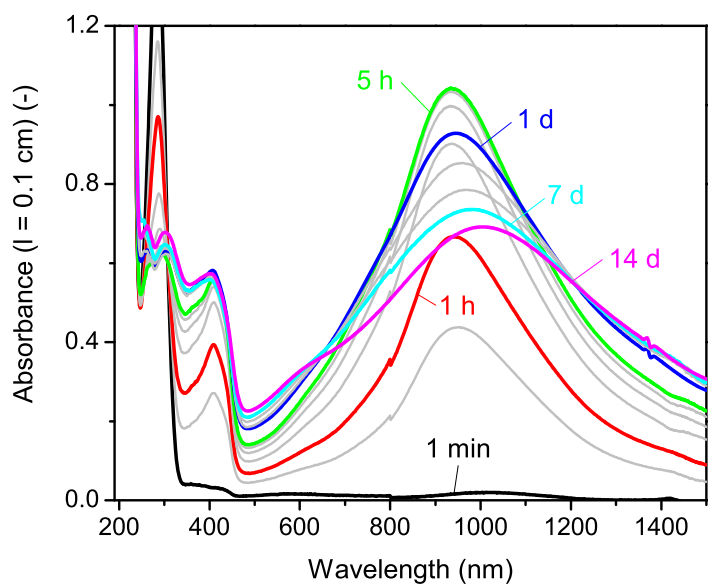

Figure 2. Changes of the UV/vis/NIR spectra of the four different reaction mixtures, as measured for samples withdrawn during the reactions. The templates used were $\mathrm{AOT}$ vesicles $(\mathrm{A},[\mathrm{AOT}]=1.5 \mathrm{mM})$, SDBS $/ \mathrm{DA}(1: 1)$ vesicles $(\mathrm{B},[\mathrm{SDBS}]=[\mathrm{DA}]=1.0 \mathrm{mM})$, SDBS micelles $(\mathrm{C}$, $[\mathrm{SDBS}]=$ $1.7 \mathrm{mM})$, and the SPS polyelectrolyte $(\mathrm{D}$, $[\mathrm{SPS}$ r.u. $]=2.9 \mathrm{mM})$. $[\mathrm{PADPA}]_{0}=1.0 \mathrm{mM},[\mathrm{TvL}]=2.6 \mathrm{nM}, \mathrm{pH}=3.5\left(\left[\mathrm{NaH}_{2} \mathrm{PO}_{4}\right]+\left[\mathrm{H}_{3} \mathrm{PO}_{4}\right]=0.1\right.$ $\mathrm{M})$, and $T \approx 25{ }^{\circ} \mathrm{C}$. For experimental details, see Section 2 . 
(A) $A_{\approx 420}$ vs. reaction time

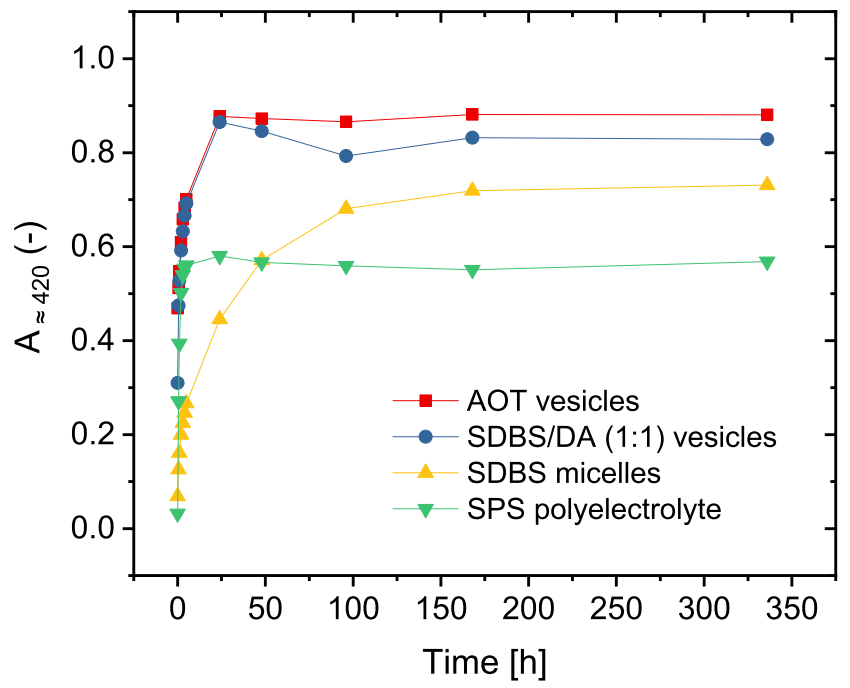

(B) $A_{\approx 1000}$ vs. reaction time



Figure 3. Time-dependent changes of $A_{\approx 420}(\mathrm{~A})$ and $A_{\approx 1000}(\mathrm{~B})$ for the four different reaction mixtures, as determined from the recorded UV/vis/ NIR spectra shown in Figure 2. The data taken for the reaction with AOT vesicles are $A_{420}$ and $A_{1070}$, with SDBS/DA (1:1) vesicles are $A_{430}$ and $A_{1100}$, with SDBS micelles are $A_{410}$ and $A_{930}$, and with the SPS polyelectrolyte are $A_{410}$ and $A_{950}$.

$\mathrm{mM}, A_{\approx 1000}$ and $A_{\approx 420}$ were lower than for $[\mathrm{SDBS}]=$ $[\mathrm{DA}]=1.0 \mathrm{mM}$ (Figure S-2A).

(b) For SDBS micelles, we considered [SDBS] $=1.7 \mathrm{mM}$ as good conditions, with absorption bands at $\lambda \approx 930$ and $410 \mathrm{~nm}$. For $[\mathrm{SDBS}]<1.1 \mathrm{mM}$, precipitation occurred, and for $[\mathrm{SDBS}]>1.8 \mathrm{mM}, A_{\approx 1000}$ and $A_{\approx 420}$ were lower than for $[\mathrm{SDBS}]=1.7 \mathrm{mM}$ (Figure $\mathrm{S}-2 \mathrm{~B})$.

(c) For SPS, there was a broad concentration range that produced very similar UV/vis/NIR spectra after a reaction time of $t=24 \mathrm{~h}$ (Figure $\mathrm{S}-2 \mathrm{C}$ ). There was, however, a slight increase in $A_{\approx 1000} / A_{\approx 500}$ when the concentration of SPS r.u., [SPS r.u.], was increased from 1.4 to $3.4 \mathrm{mM}$, whereas $A_{\approx 1000}$ and $A_{\approx 420}$ remained almost constant between 1.3 and $2.9 \mathrm{mM}$, followed by a decrease for [SPS] > $2.9 \mathrm{mM}$ (Figure S-2C). Based on this, we considered [SPS] $2.9 \mathrm{mM}$ as the optimal concentration.

3.3. Changes of the UV/Vis/NIR Spectra of the Reaction Mixtures Measured in Situ during the Reactions. For each of the four template systems, the reaction was run under the evaluated optimal reaction conditions, and the $\mathrm{UV} / \mathrm{vis} / \mathrm{NIR}$ spectra of the reaction mixtures were measured at predetermined times, up to $t=14$ days (Figure 2). The changes in the absorption at the band maxima in the NIR region of the spectra $\left(A_{\approx 1000}\right.$; assigned to the $\pi \rightarrow$ polaron transition) $)^{57}$ and at $A_{\approx 420}$ (assigned to the polaron $\rightarrow \pi^{*}$ transition $)^{57}$ are compared for all four reactions in Figure 3. From Figure 2, it is clear that in all cases the expected bands at $\lambda \approx 1000$ and $420 \mathrm{~nm}$ develop with reaction time and that the absorption at $\lambda \approx 500 \mathrm{~nm}$ remains low. Although spectral differences to some extent may be due to differences in the size of the templates (turbidity in the case of vesicle suspensions), see the DLS data of Figure 1A, there are distinct differences between the groups of spectra, which must originate from differences in the chemical structures of the actual product mixture obtained. The two vesicle systems yield very similar spectra and a very similar time-dependent evolution of the spectra with $\lambda_{\max } \approx 1070 \mathrm{~nm}$ (for AOT) and $\lambda_{\max } \approx 1100 \mathrm{~nm}$ (for SDBS/DA (1:1), Figure 2A,B). The spectra shown for the reaction run in the presence of AOT vesicles (Figure 2A) resemble closely the spectra that we recorded previously for the same reaction (Figure $2 \mathrm{~A}$ in ref 22). This indicates high reproducibility despite the complexity of the reaction (see below). For the reactions with the micellar and polyelectrolyte templates (Figure 2C,D), the spectra are different. The absorption maxima in the NIR region of the spectrum were located at $930 \mathrm{~nm}$ (for SDBS micelles) and 950 $\mathrm{nm}$ (for the SPS polyelectrolyte), respectively. For the micellar system, the absorption in the NIR region clearly originates from several absorption bands, which sum up in a very characteristic band shape (sharp absorption increase at about $850 \mathrm{~nm}$ with an increase in wavelength). A very similar spectrum was reported previously by Shumakovich et al. ${ }^{8}$ for the oxidation of PADPA in the presence of SDBS micelles at $\mathrm{pH}=3.8$ with $T$. hirsuta laccase. ${ }^{8}$ For this micellar system, significant spectral changes occur well beyond $t=1$ day; in other words, the reaction is much slower compared to the reaction with the vesicles (Figure 3 ). In the presence of the polyelectrolyte SPS, the reaction yields products with $\lambda_{\max } \approx$ $950 \mathrm{~nm}$ and strongest intensity after $t=5 \mathrm{~h}$ (Figure 2D). For $t$ $>5 \mathrm{~h}, A_{950}$ decreases with a considerable broadening of the band toward higher as well as lower wavelengths. During the complex spectral changes above $\lambda \approx 500 \mathrm{~nm}, A_{\approx 420}$ remained fairly constant (Figure 3B).

In summary, the in situ UV/vis/NIR measurements indicate that the template type has a significant influence on the kinetics of the reaction and on the absorption spectra of the products obtained. It seems that the template effect of the two vesicle systems is distinctly different from the template effect of the polyelectrolyte, and it is obvious that the reaction in the presence of SDBS micelles is very slow. After $t=1$ day and later, the highest $A_{\approx 1000}$ and $A_{\approx 420}$ values are observed for the system with AOT vesicles, indicating the highest content of the PANI-ES-polaron form obtained with this template from PADPA with TvL and $\mathrm{O}_{2}$ (Figure 3).

3.4. Changes of the EPR Spectra of the Reaction Mixtures Measured in Situ during the Reactions. The 


\section{(A) AOT vesicles}

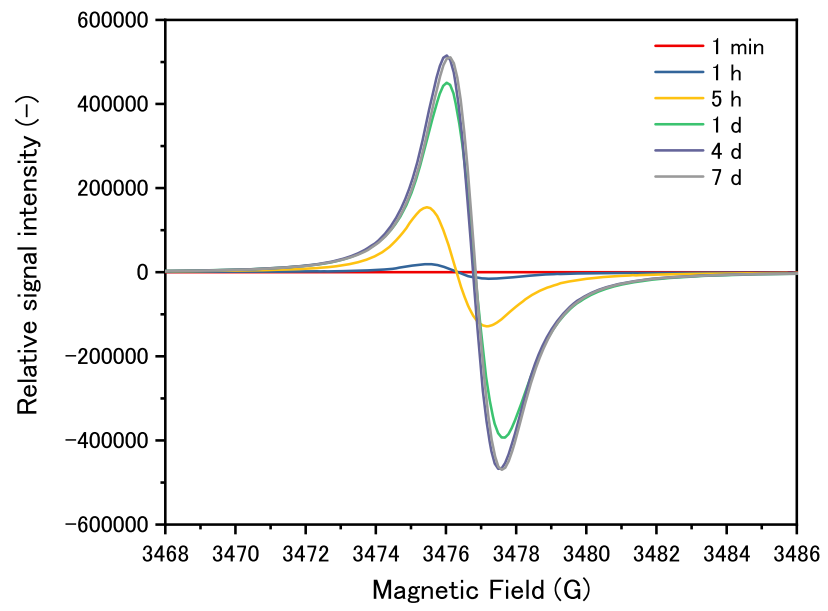

(C) SDBS micelles

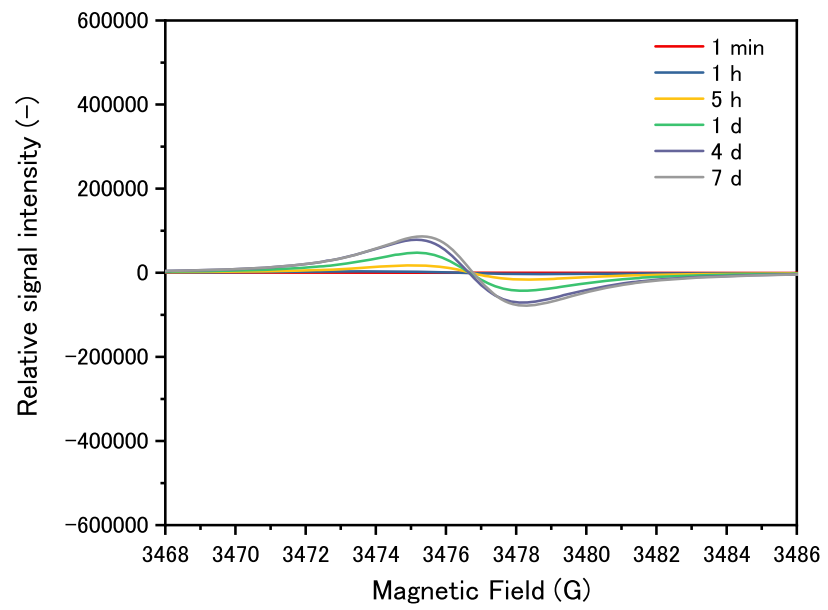

(B) SDBS/DA (1:1) vesicles

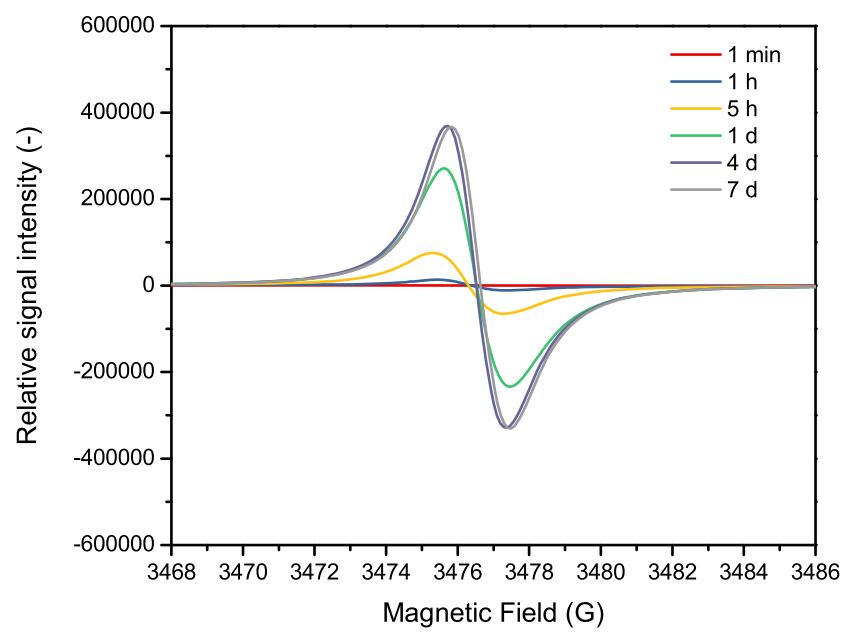

(D) SPS polyelectrolyte

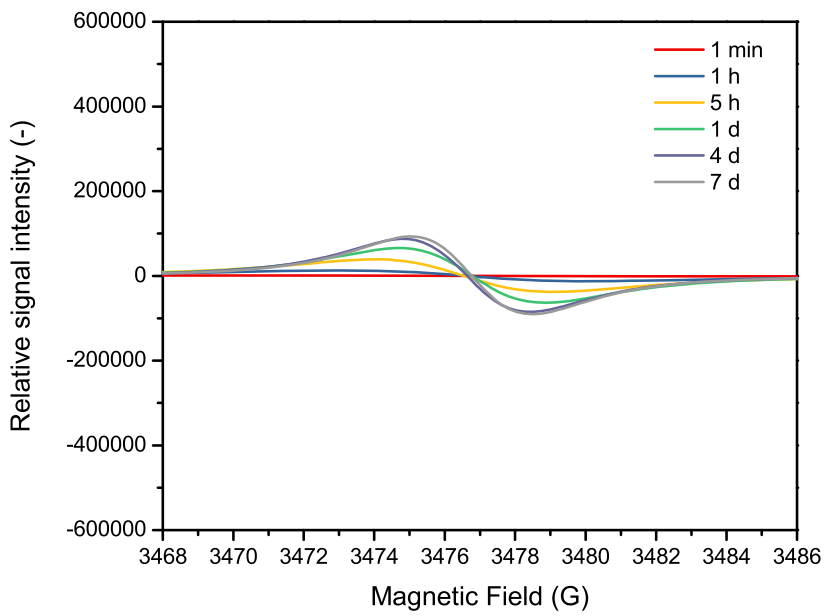

Figure 4. Changes of the EPR spectra of the four different reaction mixtures, as measured for samples withdrawn during the reactions. For the conditions, see the legend of Figure 2.

four reactions were also analyzed by EPR spectroscopy measurements up to a reaction time of $t=7$ days (Figures 4 and 5). With all templates, centers with unpaired electrons form with time, whereby their content initially increases and then levels off. Formation of radicals is expected if products with PANI-ES units in the polaron state are obtained (Scheme 1 ). For the two vesicle systems and for the SPS polyelectrolyte, a stable radical content is achieved after $t=1$ day. In the case of SDBS micelles, the radical content formation is much slower, correlating with the slow increase in $A_{\approx 1000}$; see Figure 3. Although the integral of the EPR signal after reaching saturation was about the same for the two vesicle systems and for the SPS polyelectrolyte (Figure 5), in the latter case, the EPR signal was much broader (compare Figure 4A,B with Figure 4D). Nevertheless, among the four template systems, for $t=1$ day and later, the radical content is highest for the mixture with AOT vesicles (Figure 5). SDBS micelles as a template also resulted in a broad EPR signal (Figure 4C), which developed more slowly than with the other three. Integrals obtained from spectra of chemically similar samples with reproducible sample positioning in the spectrometer are a reliable quantitative tool to compare their relative radical content.

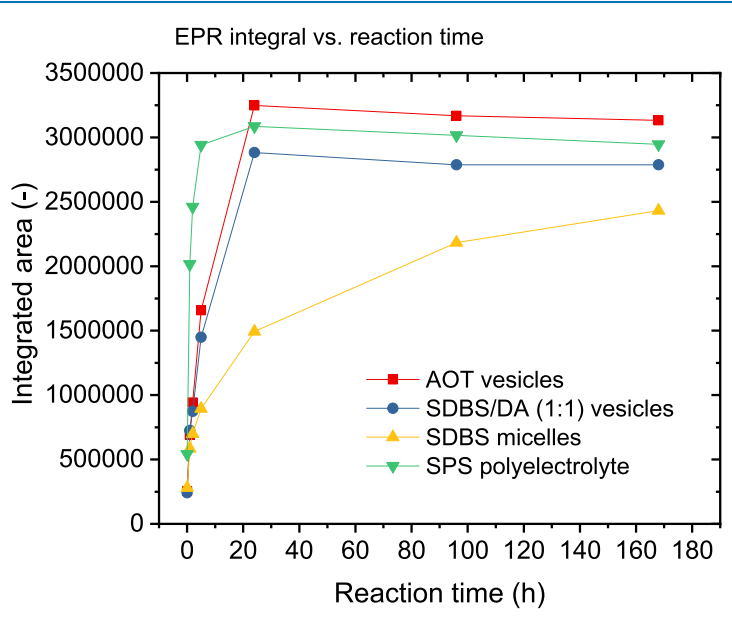

Figure 5. Time-dependent changes of the integral of the EPR signal for the four different reaction mixtures, as determined from the recorded EPR spectra shown in Figure 4.

In summary, the in situ EPR measurements qualitatively and quantitatively confirm the results of the in situ UV/vis/NIR measurements with respect to the kinetics and yields of the 
reaction, with good correlation between EPR signal intensity (integral) and $A_{\approx 1000}$. Interestingly, the fundamental type of radical formed at saturation of the reaction appears to be similar for all systems (Figure 4), with a variation in Landé $g$ factor of only 0.0003. However, the EPR line width differs significantly between products obtained in the presence of SPS or SDBS micelles compared with the two vesicle systems. The observed differences originate most likely from the regularity of the chemical environment in which the paramagnetic centers are embedded. This regularity concerns the oligomer/polymer as well as the template. We conclude that vesicles with their fairly ordered membrane help to produce a rather uniform oligomer/polymer and keep it aligned in the matrix they represent. This results in a narrow distribution of electronic states in their paramagnetic centers, causing sharper EPR bands than in the case of products obtained with the polyelectrolyte or micelle template. The latter apparently is not able to impose structural regularity on the oligomers/ polymers.

3.5. Effect of Template Type on the Activity and Stability of TvL as Measured with $\mathrm{ABTS}^{2-}$. If stored at RT in the $\mathrm{pH} 3.5$ solution at $[\mathrm{TvL}]=2.6 \mathrm{nM}$ under the same conditions used for the reaction with PADPA ( $50 \mathrm{~mL}$ flasks, 10 $\mathrm{mL}$ reaction volume), the activity of laccase drops within $5 \mathrm{~h}$ to about $50 \%$ of its initial value measured immediately after preparing the solution; after $24 \mathrm{~h}, \approx 10 \%$ of the initial activity could be measured (Figure 6). This indicates that the enzyme

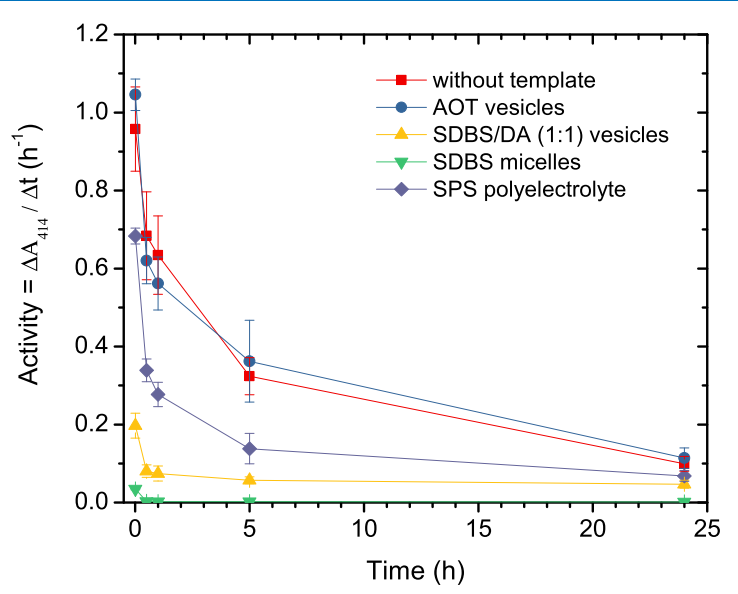

Figure 6. Relative activity and stability of TvL dissolved at $[\mathrm{TvL}]=$ $2.6 \mathrm{nM}$ and $T \approx 25{ }^{\circ} \mathrm{C}$ in $\mathrm{pH}=3.5$ solution $\left(\left[\mathrm{NaH}_{2} \mathrm{PO}_{4}\right]+\left[\mathrm{H}_{3} \mathrm{PO}_{4}\right]\right.$ $=0.1 \mathrm{M})$ in the presence of either AOT vesicles $(\bullet,[\mathrm{AOT}]=1.5$ $\mathrm{mM}), \operatorname{SDBS} / \mathrm{DA}(1: 1)$ vesicles $(\boldsymbol{\Lambda},[\mathrm{SDBS}]=[\mathrm{DA}]=1.0 \mathrm{mM})$, SDBS micelles $(\boldsymbol{\nabla},[$ SDBS $]=1.7 \mathrm{mM})$, or the SPS polyelectrolyte $(\diamond$, [SPS r.u.] $=2.9 \mathrm{mM})$. For comparison, TvL dissolved in the $\mathrm{pH}$ 3.5 solution without any added template was also analyzed ( $\mathbf{\square})$. The activity was measured with $0.25 \mathrm{mM} \mathrm{ABTS}^{2-}$ as the substrate at $\mathrm{pH}=$ $3.5(l=1.0 \mathrm{~cm})$; see Section 2 . The activity is expressed as change in $A_{414}\left(\Delta A_{414}\right)$, indicative of the formation of $\mathrm{ABTS}^{\bullet}{ }^{-}$, per time unit $(\Delta t)$ measured. Average values and standard deviations from three separately prepared samples are plotted for each condition.

is not very stable in such dilute solution. The presence of AOT vesicles (1.5 mM AOT) has no significant influence on the stability of TvL. In contrast, the TvL activity was very low in the presence of SDBS micelles (1.7 mM SDBS), even for the measurements that were done immediately after adding TvL to the SDBS solution (time $1 \mathrm{~min}$ ) (Figure 6). A similar situation was found for SDBS/DA $(1: 1)$ vesicles $([\mathrm{SDBS}]=[\mathrm{DA}]=1.0$
$\mathrm{mM}$ ), although the activity decrease was not that dramatic (Figure 6). For the SPS polyelectrolyte, the TvL activity also decreased significantly with storage time (Figure 6). Although these $\mathrm{TvL}$ storage stability measurements may not reflect the operational stability of TvL, i.e., the activity change in the presence of PADPA, ${ }^{19}$ it at least explains qualitatively why the $\mathrm{TvL} / \mathrm{O}_{2}$-catalyzed oxidation and oligomerization of PADPA in the presence of SDBS micelles are much slower compared with the reaction with the other three templates (Figures 3 and 5). Therefore, for the following investigations we did not consider SDBS micelles as a template anymore for the low concentration of TvL (2.6 nM) and only compared the two vesicle systems and the SPS polyelectrolyte. However, later on, we reconsidered SDBS micelles using a 10 times higher TvL concentration ( $26 \mathrm{nM})$; see below.

3.6. Reproducibility for the Reactions in the Presence of AOT Vesicles, SDBS/DA (1:1) Vesicles, or SPS Polyelectrolyte as Templates. Since the reaction mixtures investigated are heterogeneous and consist of (i) fluid and dynamic polymolecular assemblies (vesicles or micelles) or dynamically clustering polyelectrolytes, ${ }^{76-78}$ (ii) enzyme molecules with low storage stability, (iii) $\mathrm{O}_{2}$ as reoxidant of the enzyme, and (iv) PADPA monomers that have a low water solubility, the reproducibility of the experiments needs to be addressed. Therefore, for each of the three conditions, we have prepared three reaction mixtures in exactly the same way (see Section 2), and after a reaction time of $t=24 \mathrm{~h}$ at $T \approx 25^{\circ} \mathrm{C}$, the reaction mixtures were analyzed by in situ UV/vis/NIR and in situ EPR spectroscopy measurements. The results are shown in Figure 7. Good reproducibility was observed for AOT vesicles, in agreement with our previous results, ${ }^{22}$ and for the SPS polyelectrolyte. In the case of SDBS/DA (1:1) vesicles, there was considerable variation. The reason for this is not clear. It may, however, originate from the more severe TvL inhibition in the presence of this type of vesicles, as compared with the AOT vesicles or SPS polyelectrolyte (Figure 6).

3.7. Raman Spectroscopy Measurements. The three reaction mixtures containing either AOT vesicles, SDBS/DA (1:1) vesicles, or the SPS polyelectrolyte as templates were analyzed by in situ Raman spectroscopy measurements after running the reactions for $24 \mathrm{~h}$ at RT. In the case of SPS, the spectrum was also measured after $t=5 \mathrm{~h}$ (Figure 8) since after $5 \mathrm{~h}$ of reaction in the presence of SPS, the intensity of the peak in the NIR region of the absorption spectrum was highest (see Figure 2). The Raman spectrum recorded for the AOT vesicle system shown in Figure 8 (top) is the same as the one shown in Figure 5 of Kashima et al. ${ }^{22}$ The spectrum is replotted here to allow an easier comparison among the different template systems. The time-dependent changes in the Raman spectrum for the reaction in the presence of AOT vesicles, ${ }^{22}$ SDBS/DA (1:1) vesicles, and the SPS polyelectrolyte recorded during the reaction are shown in Figures S-3-S-5, respectively.

At first glance, the spectra recorded after $t=24 \mathrm{~h}$ (Figure 8) look very similar for the three templates and contain the same main bands. However, some differences exist. The Raman spectra of all reaction systems for $t=24 \mathrm{~h}$ exhibit bands that are characteristic of polyaniline in its conductive emeraldine salt form (PANI-ES). They are positioned at 1623-1627 $\mathrm{cm}^{-1}$ $\left(\mathrm{C} \sim \mathrm{C}\right.$ stretching vibrations of benzenoid $(\mathrm{B})$ rings, $\nu(\mathrm{C} \sim \mathrm{C})_{\mathrm{B}}$, where " $\sim$ " denotes a bond intermediate between the single and the double bond), 1592-1597 $\mathrm{cm}^{-1} \quad(\mathrm{C}=\mathrm{C}$ and $\mathrm{C} \sim \mathrm{C}$ stretching vibrations of quinonoid $(\mathrm{Q})$ and semiquinonoid (SQ) rings, $\nu(\mathrm{C}=\mathrm{C})_{\mathrm{Q}}$ and $\left.\nu(\mathrm{C} \sim \mathrm{C})_{\mathrm{SQ}}\right), 1510-1513 \mathrm{~cm}^{-1}$ 


\section{(A) AOT vesicles}

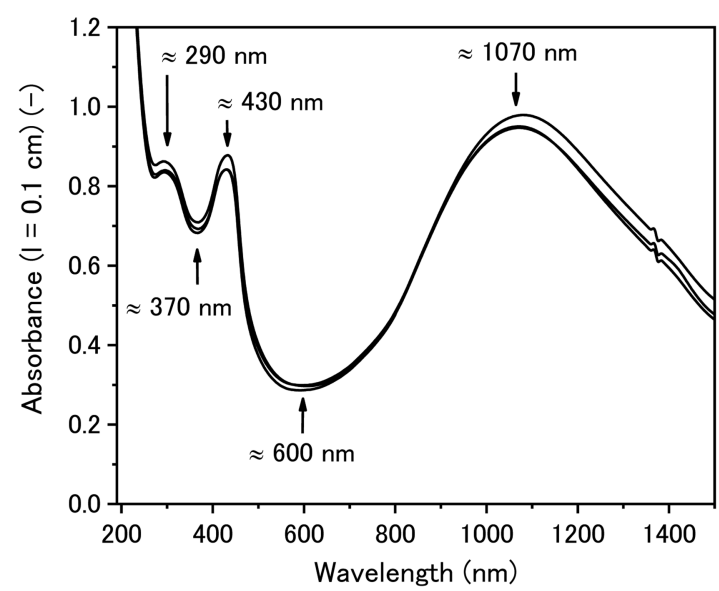

(C) SDBS/DA (1:1) vesicles

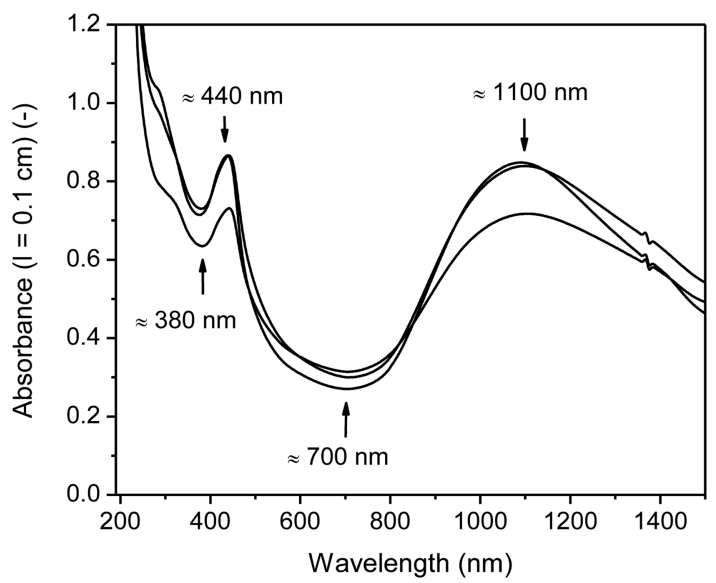

(E) SPS polyelectrolyte

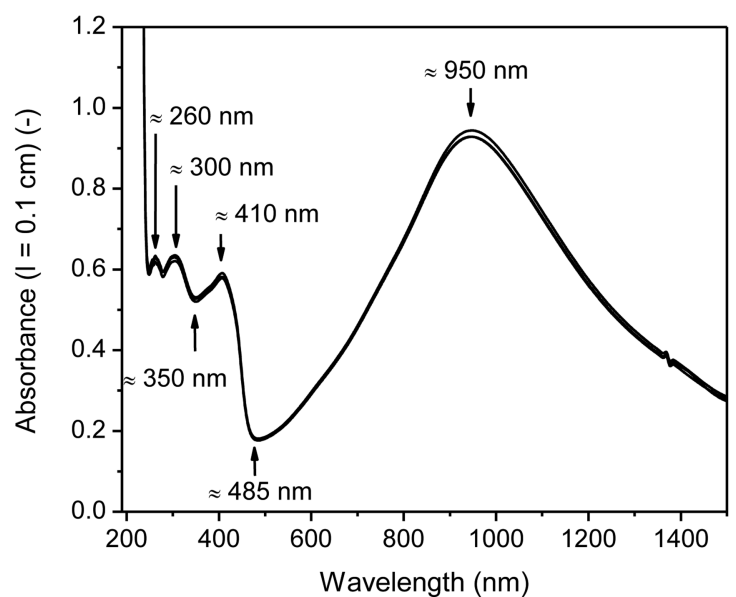

(B) AOT vesicles

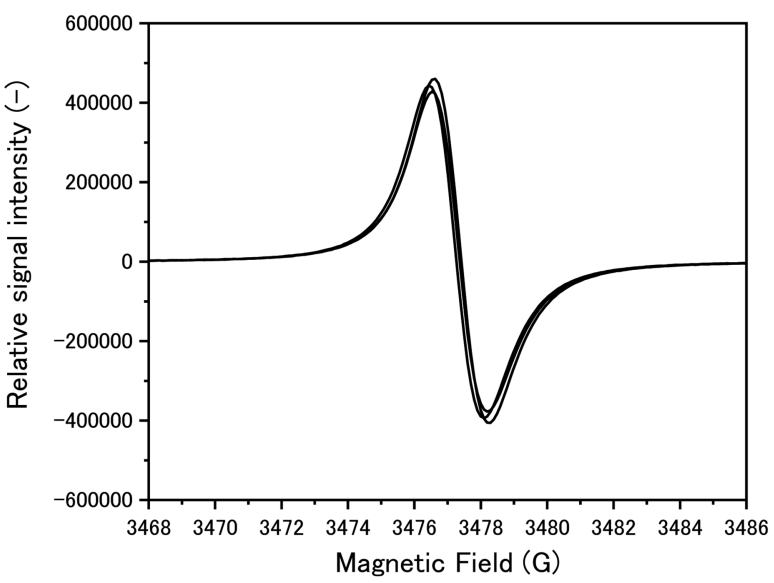

(D) SDBS/DA (1:1) vesicles

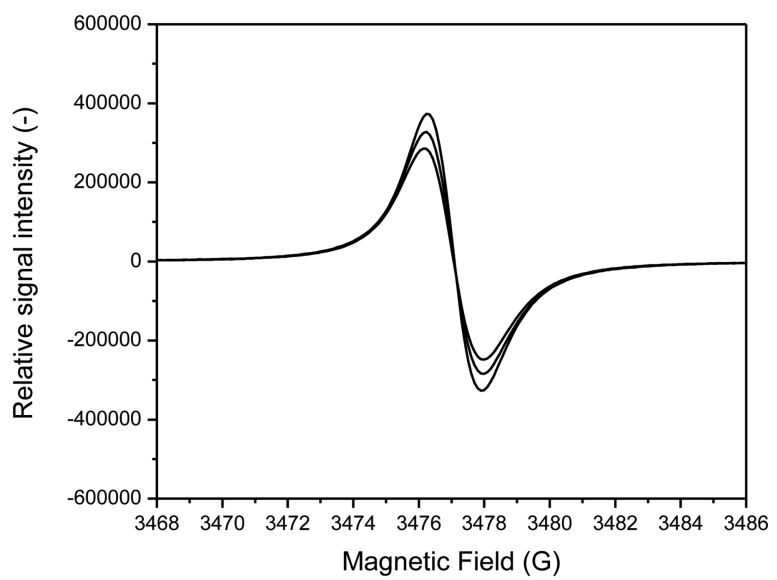

(F) SPS polyelectrolyte

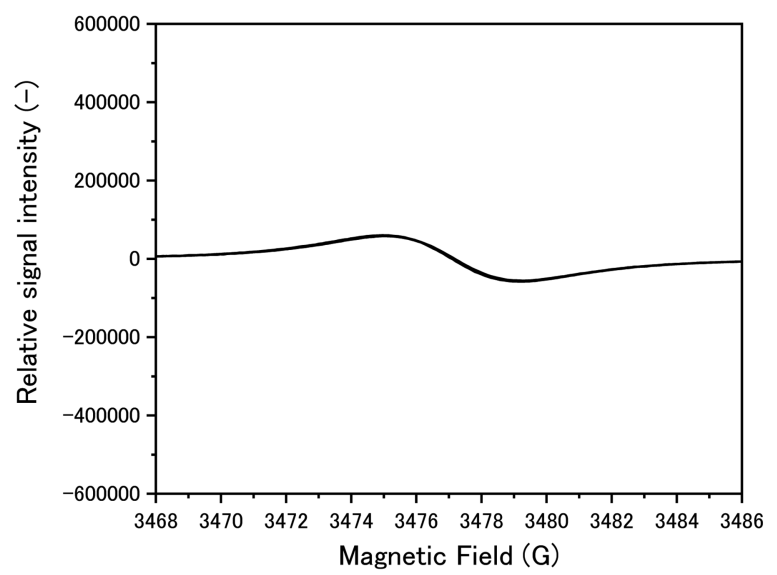

Figure 7. Reproducibility tests for the TvL/ $\mathrm{O}_{2}$-catalyzed oxidation and oligomerization of PADPA in the presence of either AOT vesicles (A, B), SDBS/DA (1:1) vesicles (C, D), or the SPS polyelectrolyte (E, F). For each condition, three reactions were run with $[\mathrm{TvL}]=2.6 \mathrm{nM}$ at $25^{\circ} \mathrm{C}$ for $24 \mathrm{~h}$. Shown are the recorded in situ UV/vis/NIR (A, C, E) and in situ EPR (B, D, F) spectra. For the reaction conditions, see the legend of Figure 2.

$(\mathrm{N}-\mathrm{H}$ bending vibration, $\delta(\mathrm{N}-\mathrm{H})), 1351-1358 \mathrm{~cm}^{-1}$ with a shoulder at $1318-1330 \mathrm{~cm}^{-1}\left(\mathrm{C}-\mathrm{N}^{\bullet+}\right.$ stretching vibrations in polaronic SQ structures, $\left.\nu\left(\mathrm{C}-\mathrm{N}^{\bullet+}\right)_{\mathrm{SQ}}\right)$, and $1179-1189 \mathrm{~cm}^{-1}$ $\left(\mathrm{C}-\mathrm{H}\right.$ bending in-plane vibrations of $\mathrm{B}$ rings, $\left.\delta(\mathrm{C}-\mathrm{H})_{\mathrm{B}}\right)$ with a shoulder at $\approx 1165 \mathrm{~cm}^{-1}(\mathrm{C}-\mathrm{H}$ bending in-plane vibrations of SQ rings, $\left.\delta(\mathrm{C}-\mathrm{H})_{\mathrm{SQ}}\right)$ observed for systems with AOT vesicles and SDBS/decanoic acid vesicles (Figure 8). ${ }^{38,80}$ Particularly indicative of a good electrical conductivity of the 


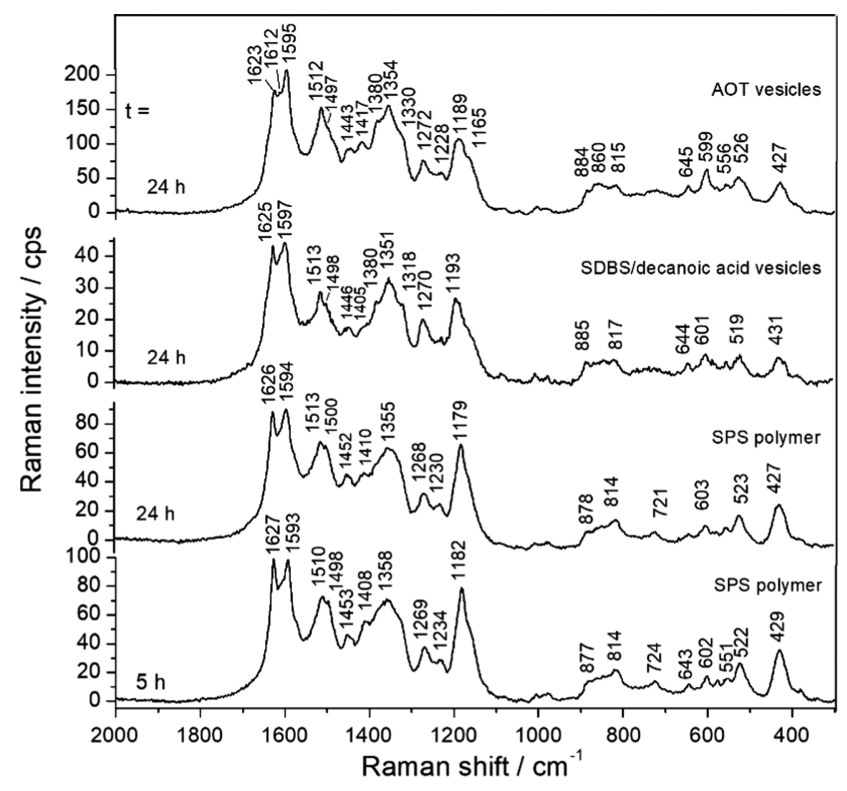

Figure 8. Analysis of reaction mixtures by in situ Raman spectroscopy measurements for the $\mathrm{TvL} / \mathrm{O}_{2}$-catalyzed PADPA oxidation/oligomerization reactions run either in the presence of AOT vesicles, SDBS/ DA (1:1) vesicles, or the SPS polyelectrolyte as templates. The Raman spectra were recorded after $t=24 \mathrm{~h}$. For SPS, a measurement was also made after $t=5 \mathrm{~h}$. Excitation wavelength: $633 \mathrm{~nm}$. For the reaction conditions, see the legend of Figure 2. For experimental details, see Section 2.

obtained products is the strong "polaron band", $\nu\left(\mathrm{C}-\mathrm{N}^{\bullet+}\right)_{\mathrm{SQ}}$, observed in all Raman spectra, as well as the shoulder at $\approx 1165$ $\mathrm{cm}^{-1}$ observed only for the systems with vesicles as templates. These features correlate well with the strong band observed in the UV/vis/NIR spectra at 930-1100 nm (Figure 2). Besides the mentioned bands, the spectra for the systems with SDBS/ DA $(1: 1)$ vesicles and the SPS polyelectrolyte exhibit a peak at about $1498 \mathrm{~cm}^{-1}$ (barely discernible for the system with AOT vesicles), which can be assigned to the $\mathrm{C}=\mathrm{N}$ stretching vibration in $\mathrm{Q}$ rings (i.e., in quinonediimine units), $\nu(\mathrm{C}=\mathrm{N})_{\mathrm{Q}} \cdot{ }^{38,80}$

Raman bands that are not typical for ordinary PANI are also seen in the spectra of the reaction products obtained in the presence of the three different templates, recorded at $t=24 \mathrm{~h}$ (Figure 8). They can be attributed to branched and phenazinetype structural units and are seen at $1443-1454 \mathrm{~cm}^{-1}$ (attributable to ring $\mathrm{C}=\mathrm{C}$ stretching vibrations, possibly in short branches/short chains and in substituted phenazine- and $N$-phenylphenazine-type structures), $1408-1417 \mathrm{~cm}^{-1}$ (attributed to phenazine-type units), and $1380 \mathrm{~cm}^{-1}$ (its origin is still debatable, and it is attributable to $\nu\left(\mathrm{C}-\mathrm{N}^{+}\right)$vibrations in $N$ phenylphenazine units and/or to $\nu\left(\mathrm{C}-\mathrm{N}^{\bullet+}\right)$ vibrations in localized polaron sites). ${ }^{38}$ The appearance and positions of these bands vary with the template type, indicating fine differences in the molecular structure of the reaction products. They are seen at following wavenumbers: 1443, 1417, and $1380 \mathrm{~cm}^{-1}$ for AOT vesicles; 1446,1405 , and $1380 \mathrm{~cm}^{-1}$ for SDBS/DA (1:1) vesicles; and at 1452 and $1410 \mathrm{~cm}^{-1}$ for the SPS polyelectrolyte.

The Raman spectra of the products formed in the presence of SPS as template recorded at $t=5$ and $24 \mathrm{~h}$ are mutually very similar. One observed difference, however, refers to the intensity ratio of the bands that are atypical for PANI-ES, at about 1408 and $1453 \mathrm{~cm}^{-1}$ : in the spectrum recorded at $t=5$ $\mathrm{h}$, the band at $1408 \mathrm{~cm}^{-1}$ is noticeably stronger than the band at $1453 \mathrm{~cm}^{-1}$, whereas at $t=24 \mathrm{~h}$, these two bands have similar intensities.

For the in situ Raman spectra recorded during the reaction, before reaction equilibrium was reached (Figures S-3-S-5), one of the important features is that the strong "phenazine band" at around $1410 \mathrm{~cm}^{-1}$ appears already at the early stage of the reaction (at $t=1 \mathrm{~min}$ ) and the relative intensity of this band decreases with the reaction time for all three template systems. Another important observation refers to the evolution of polaron band due to the $\nu\left(\mathrm{C}-\mathrm{N}^{\bullet+}\right)_{\mathrm{SQ}}$ vibration (at around $1350 \mathrm{~cm}^{-1}$, with a shoulder at $\approx 1320 \mathrm{~cm}^{-1}$ ) with reaction time. The dynamics of the evolution of this band is different for each template system. For example, the first spectrum at $t=$ 1 min exhibits the $\nu\left(\mathrm{C}-\mathrm{N}^{\bullet+}\right)_{\mathrm{SQ}}$ band at around $1350 \mathrm{~cm}^{-1}$ as rather strong one in the case of AOT vesicles (Figure S-3), ${ }^{22}$ whereas in the cases of SDBS/DA (1:1) vesicles (Figure S-4) and the SPS polyelectrolyte (Figure S-5), this band is weak at $t$ $=1 \mathrm{~min}$. For all three templates, the relative intensity of the $\nu\left(\mathrm{C}-\mathrm{N}^{\bullet+}\right)_{\mathrm{SQ}}$ band increases with reaction time and it becomes strong at $t=24 \mathrm{~h}$, indicating an increase in the relative amount of polaron units, i.e., the increase in the content of conductive PANI-ES-like structural units.

3.8. HPLC Analysis. The three reaction mixtures containing either AOT vesicles, SDBS/DA (1:1) vesicles, or the SPS polyelectrolyte were also analyzed with an HPLC method, which we developed previously. ${ }^{21,22}$ In brief, with this analysis, it is possible to get information about the extent of monomer conversion (consumption of PADPA) and about the type of oligomeric products formed in the reaction mixture. Since the HPLC analysis is based on the chromatographic separation of extracted reaction products that are first deprotonated for making them extractable and then chemically reduced, no information about the oxidation and protonation states of the as-formed products can be obtained. Nevertheless, the HPLC analysis turned out to be very useful for analyzing the enzymatic oxidation and oligomerization of PADPA, as a complementary method to the in situ UV/vis/NIR, EPR, and Raman spectroscopy measurements. ${ }^{21-24}$

The chromatograms shown in Figure 9 were obtained from an HPLC analysis in which a diode array detector was used. For the AOT vesicle system (Figure 9A), the data shown are the same as in our previous work; see Figure 6A in Kashima et al. $^{22}$ The analysis was made after a reaction time of $t=24 \mathrm{~h}$. The peak pattern shown was reproducibly obtained by analyzing independently prepared reaction mixtures of the same composition. ${ }^{22}$ For the SDBS/DA (1:1) vesicles (Figure 9B), the chromatogram for $t=24$ is very similar to the chromatogram for the AOT vesicle system. For the SPS polyelectrolyte, a complete extraction of the reaction products into tert-butyl methyl ether (MTBE) after a runtime of $t=24 \mathrm{~h}$ was not possible (most likely due to a strong binding of SPS to the products or due to the formation of insoluble products). In contrast, complete product extraction was observed after $t=5$ $\mathrm{h}$, the reaction time at which the band intensity at $\lambda \approx 1000$ $\mathrm{nm}$ in the in situ UV/vis/NIR absorption spectrum was highest (Figure 2D). The HPLC analysis of the products obtained after $t=5 \mathrm{~h}$ in the presence of the SPS polyelectrolyte showed that there is a great similarity in terms of peak pattern when compared to that of the two vesicle systems (Figure $9 \mathrm{~A}, \mathrm{~B})$, the only difference being the relative intensities of the peaks. For an HPLC analysis of the progress of the reactions for all three templates, see Figure S-6. For a detailed 
(A) AOT vesicles with $[\mathrm{TvL}]=2.6 \mathrm{nM}, 24 \mathrm{~h}$

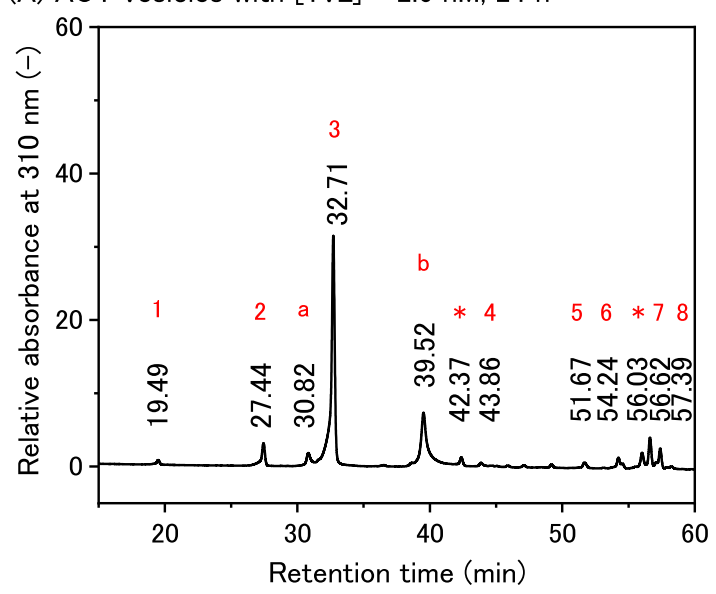

(C) SPS polymer with $[\mathrm{TVL}]=2.6 \mathrm{nM}, 5 \mathrm{~h}$

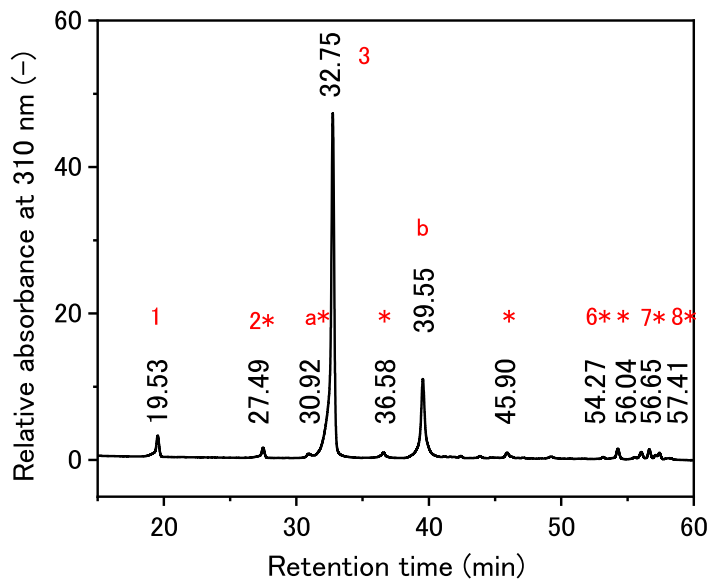

(B) SDBS/DA vesicles with $[\mathrm{TvL}]=2.6 \mathrm{nM}, 24 \mathrm{~h}$

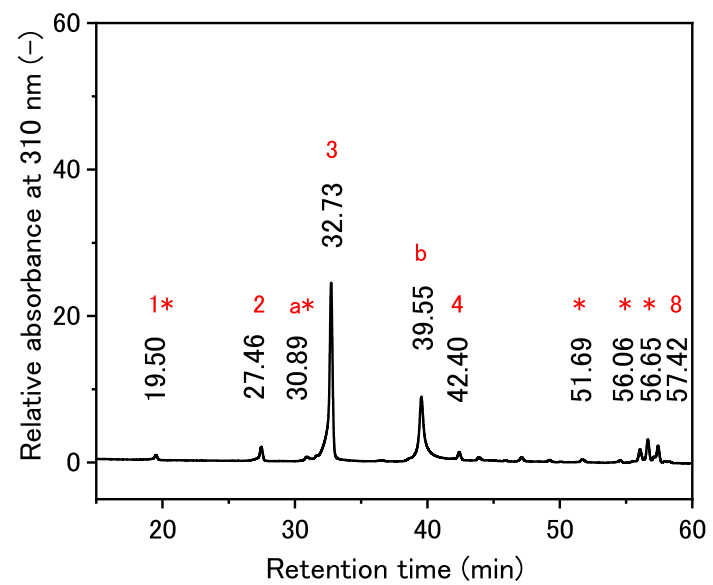

Figure 9. Chromatograms of the extracted and reduced products of the oxidation of PADPA with $\mathrm{TvL} / \mathrm{O}_{2}$ in the presence of either AOT vesicles $([\mathrm{AOT}]=1.5 \mathrm{mM})(\mathrm{A})$; SDBS $/ \mathrm{DA}(1: 1)$ vesicles $([\mathrm{SDBS}]=[\mathrm{DA}]=1.0 \mathrm{mM})(\mathrm{B})$; or the SPS polyelectrolyte $([\mathrm{SPS}$ r.u. $]=2.9 \mathrm{mM})(\mathrm{C})$. For all reaction mixtures, $[\mathrm{TvL}] \approx 2.6 \mathrm{nM} ;[\mathrm{PADPA}]=1.0 \mathrm{mM} ; \mathrm{pH}=3.5\left(\left[\mathrm{NaH}_{2} \mathrm{PO}_{4}\right]+\left[\mathrm{H}_{3} \mathrm{PO}_{4}\right]=0.1 \mathrm{M}\right)$, and $\mathrm{T} \approx 25^{\circ} \mathrm{C}$. Analysis was performed after $t=24 \mathrm{~h}$ (for (A) and (B)) or $t=5 \mathrm{~h}(\mathrm{C})$. All products presented here were extracted into MTBE.

Table 1. Assignment of the Main Peaks in the HPLC Chromatograms Shown in Figure 9; See Kashima et al. (2018) ${ }^{22}$ for Details

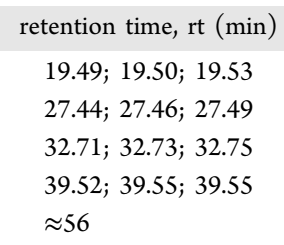

assignment of the different peaks based on an HPLC-MS analysis with partially deuterated PADPA monomers, see Kashima et al., ${ }^{22}$ and Table 1.

Overall, the HPLC analysis of the deprotonated and reduced reaction products shows that the two vesicle systems gave very similar results after $t=24 \mathrm{~h}$ (Figure 9A,B) and that in the case of SPS the product distribution in the reaction is also very similar when analyzed after $t=5 \mathrm{~h}$ (Figure 9C). The main product is the linear aniline tetramer, (PADPA) 2 (eluting after $\mathrm{rt} \approx 32.7 \mathrm{~min})$. Furthermore, linear hexaaniline is formed, $(\mathrm{PADPA})_{3}$ (eluting after $\mathrm{rt} \approx 39.5 \mathrm{~min}$ ), as well as higher oligomers with phenazine units (eluting at $\mathrm{rt} \approx 56 \mathrm{~min}$ ). The amount of remaining PADPA monomer, which elutes at $\mathrm{rt} \approx$ $19.5 \mathrm{~min}^{22}$ was very low. In the case of SPS, the difficulty of molecular formula (for chemical structure, see Scheme S-2)

$$
\begin{aligned}
& \mathrm{C}_{12} \mathrm{H}_{13} \mathrm{~N}_{2}^{+} \\
& \mathrm{C}_{18} \mathrm{H}_{16} \mathrm{~N}_{3}^{+} \\
& \mathrm{C}_{24} \mathrm{H}_{23} \mathrm{~N}_{4}^{+}\left(\mathrm{C}_{24} \mathrm{H}_{21} \mathrm{~N}_{4}^{+}\right) \\
& \mathrm{C}_{36} \mathrm{H}_{32} \mathrm{~N}_{6}^{+} \\
& \mathrm{C}_{48} \mathrm{H}_{41} \mathrm{~N}_{8}^{+} \text {for example }
\end{aligned}
$$

completely extracting the products formed after a reaction time of $t=24 \mathrm{~h}$ seems to be linked to the observation made with the in situ Raman spectroscopy measurements; see Section 3.7 (Figure S-5). Spectral changes occur between $t=5$ and $24 \mathrm{~h}$ in Raman bands, which are atypical for PANI-ES and therefore undesired (possible transformation of short branches into phenazine structures).

3.9. Test of the Inkjet-Printability of the PANI-ES Suspensions Obtained with AOT Vesicles, SDBS/DA $(1: 1)$ Vesicles, or SPS Polyelectrolyte. All three reaction mixtures were tested for their inkjet-printability on ordinary white paper by applying a previously developed protocol. ${ }^{17}$ The original black ink of a commercial thermal inkjet cartridge, after modification to accommodate lower-surface-tension inks, 


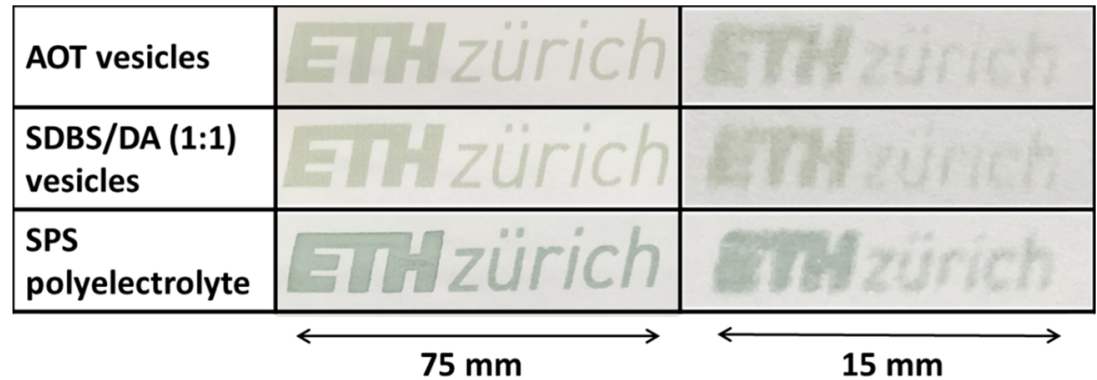

Figure 10. Photographs of inkjet-printed patterns using three different reaction mixtures obtained from the enzymatic oligomerization of PADPA in the presence of either AOT vesicles, SDBS/DA (1:1) vesicles, or the SPS polyelectrolyte as templates with TvL/O $\mathrm{O}_{2}$ after a reaction time of $t=24$ h. For the composition, see the legend of Figure 9. Pictures on the left side are large size characters with $75 \mathrm{~mm}$ total width. Pictures on the right side are small patterns with $15 \mathrm{~mm}$ width.

was replaced by a PANI-ES template suspension or solution. As a result, all three reaction mixtures could be used as ink without any further pretreatment (Figure 10). Consistent and continual printing over many pages was possible, indicating small and well-dispersed particles present in the reaction mixtures in all cases. Neither clogging of the inkjet printer nozzles nor thermal decomposition of the inks was observed. This is important for possible applications of the as-obtained PANI-ES template dispersion or solutions.

3.10. Reconsidering SDBS Micelles by Using a Significantly Higher TvL Concentration. In the final part of this work, we reconsidered the use of SDBS micelles as templates and tried to apply a higher TvL concentration for achieving complete PADPA conversion. All chosen conditions were the same: $[\mathrm{SDBS}]=1.7 \mathrm{mM},[\mathrm{PADPA}]=1.0 \mathrm{mM}, \mathrm{pH}=$ 3.5 solution, and $T \approx 25{ }^{\circ} \mathrm{C}$. The concentration of TvL was varied between 2.6 and $26 \mathrm{nM}$. The UV/vis/NIR spectra recorded after a reaction time of $t=24 \mathrm{~h}$ are shown in Figure 11 . For $[\mathrm{TvL}] \approx 2.6 \mathrm{nM}$, the spectrum is about the same as the one shown in Figure 2D for $t=1$ day, with $\lambda_{\max } \approx 930$ and 440 $\mathrm{nm}$. For $[\mathrm{TvL}]=26 \mathrm{nM}$, both band intensities were considerably higher. For the reaction mixture at these "new

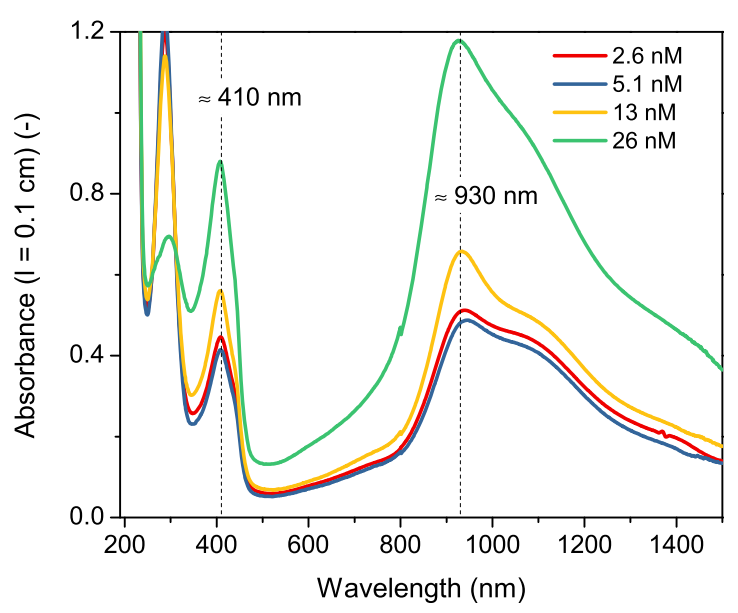

Figure 11. Effect of TvL concentration on the in situ UV/vis/NIR spectrum of the reaction products obtained from the enzymatic oligomerization of PADPA in the presence of SDBS micelles as templates. The reaction was carried out at $[\mathrm{SDBS}]=1.7 \mathrm{mM}$, $[\mathrm{PADPA}]=1.0 \mathrm{mM}, \mathrm{pH}=3.5\left(\left[\mathrm{NaH}_{2} \mathrm{PO} 4\right]+\left[\mathrm{H}_{3} \mathrm{PO} 4\right]=0.1 \mathrm{M}\right)$, and $T \approx 25{ }^{\circ} \mathrm{C}$; and [TvL] varying between 2.6 and $26 \mathrm{nM}$. For all TvL concentrations, characteristic peaks appeared at $\lambda \approx 930$ and 410 nm. For experimental details, see Section 2.
SDBS micelle conditions" with $26 \mathrm{nM}$ TvL, we carried out the same analysis as for the other three reaction mixtures and $\approx 2.6$ $\mathrm{nM}$ TvL-AOT vesicles, SDBS/DA (1:1) vesicles, and SPS polyelectrolyte; see Figure 12. The results obtained can be summarized as follows. Although after a reaction time of $t=24$ $\mathrm{h}$ high absorbance at $\lambda \approx 930 \mathrm{~nm}$ is reached, the UV/vis/NIR spectrum continues to change with time up to at least $t=14$ days with an increase in absorbance between 1100 and 1400 $\mathrm{nm}$ and a slight decrease in $A_{\approx 930}$ (Figure 12A). The EPR signal is always broad, and its intensity increases with reaction time, even beyond $t=1$ day (Figure $12 \mathrm{~B}$ ). The reproducibility of the measurements is high (Figure 12C,D). The Raman spectrum recorded after $t=24 \mathrm{~h}$ (Figure 12E) is very similar to the Raman spectra of the reaction mixtures in the presence of vesicles and polyelectrolyte templates at $[\mathrm{TvL}]=2.6 \mathrm{nM}$. As discussed in Section 3.7, bands are also present at 1454 and $1394 \mathrm{~cm}^{-1}$, which are atypical for PANI-ES and indicate the formation of structure units containing substituted phenazines and branches. For SDBS micelles as templates, the relative intensity of the band at $1394 \mathrm{~cm}^{-1}$ at $t=24 \mathrm{~h}$ is much higher (Figure S-7) compared to that of the spectra of the products obtained with the other three templates at $t=24 \mathrm{~h}$, at the same $\mathrm{TvL}$ concentration (Figures S-3-S-5). The time-dependent changes in the Raman spectrum are shown in Figure S-7. Similar to the case of AOT vesicles, the polaron band due to the $\nu\left(\mathrm{C}-\mathrm{N}^{\bullet+}\right)_{\mathrm{SQ}}$ vibration at $1350 \mathrm{~cm}^{-1}$ is rather strong already after $t=1 \mathrm{~min}$. The HPLC data (Figures $12 \mathrm{~F}$ and S-8) are very similar to the ones shown for the other templates and 2.6 nM TvL conditions. Finally, the inkjet-printability of the SDBS reaction mixture obtained with $26 \mathrm{nM}$ TvL after $T=24$ $\mathrm{h}$ has been confirmed (Figure 12G). Overall, it can be concluded that a much higher TvL concentration is needed for the system with SDBS micelles to achieve high monomer conversion and similar characteristics of PADPA oligomeric products within $24 \mathrm{~h}$ compared to that needed for the systems with the other three templates $(2.6 \mathrm{nM})$.

\section{CONCLUSIONS}

In a follow-up work of our previous investigations of the TvL/ $\mathrm{O}_{2}$-catalyzed oxidation and oligomerization of PADPA in the presence of AOT vesicles as templates for obtaining conductive PANI-ES-type products, ${ }^{19-22}$ we have made a comparison of the same reaction but with SDBS/DA (1:1) vesicles, SDBS micelles, or the SPS polyelectrolyte as templates. For the optimized conditions used, the products obtained with the two vesicle templates have more in common than the products of the reactions in the presence of SPS 
(A) UV/vis/NIIR; SDBS micelles, $26 \mathrm{nM}$ TVL

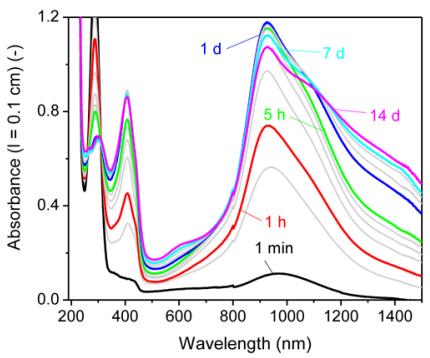

(C) UV/vis/NIR; SDBS micelles, $26 \mathrm{nM}$ TvL, $24 \mathrm{~h}$

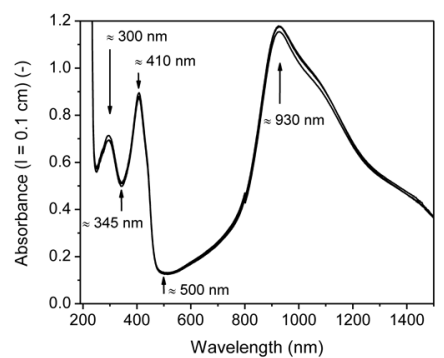

(B) EPR; SDBS micelles, $26 \mathrm{nM}$ TVL

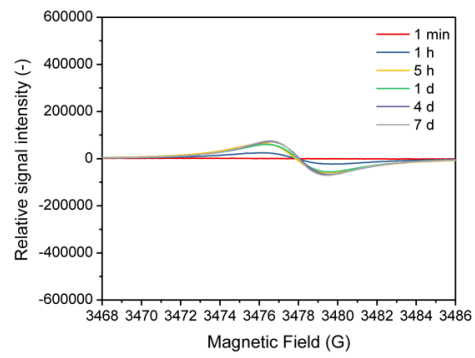

(D) EPR; SDBS micelles, $26 \mathrm{nM} \mathrm{TVL}, 24 \mathrm{~h}$

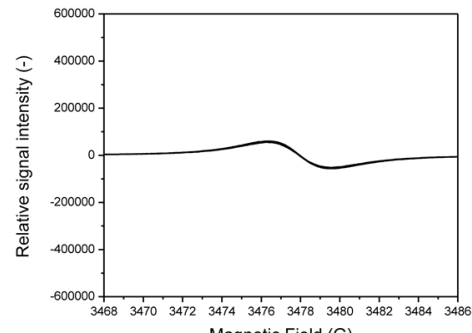

(E) Raman; SDBS micelles, $26 \mathrm{nM} \mathrm{TVL}, 24 \mathrm{~h}$

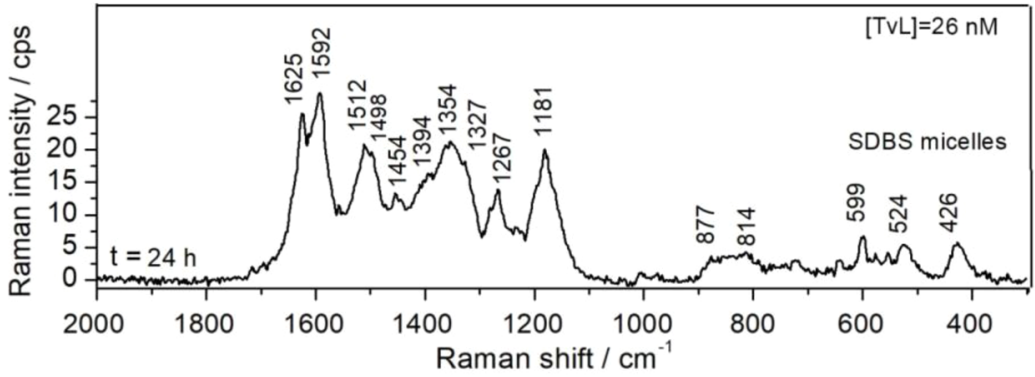

(F) HPLC; SDBS micelles, $26 \mathrm{nM} \mathrm{TvL,} 24 \mathrm{~h}$

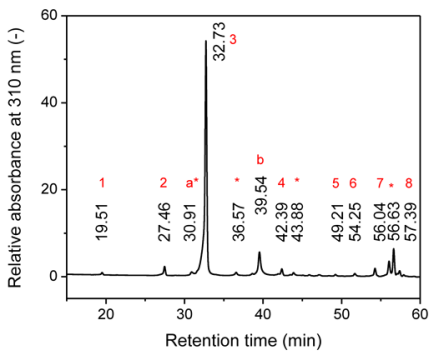

(G) Inkjet printed on paper; SDBS micelles, $26 \mathrm{nM}$ TVL, $24 \mathrm{~h}$

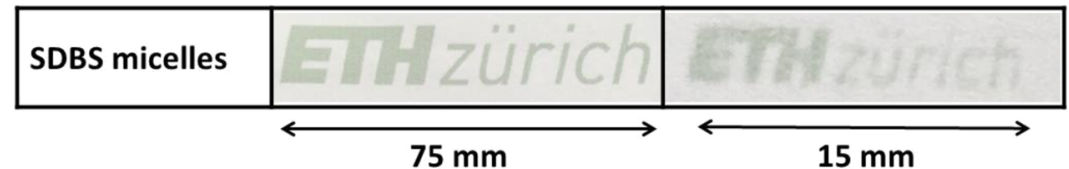

$75 \mathrm{~mm}$

$15 \mathrm{~mm}$

Figure 12. Reconsidering the SDBS micelles using $26 \mathrm{nM}$ instead of $2.6 \mathrm{nM}$ TvL. The reaction was carried out at $[\mathrm{SDBS}]=1.7 \mathrm{mM},[\mathrm{PADPA}]=$ $1.0 \mathrm{mM}, \mathrm{pH}=3.5\left(\left[\mathrm{NaH}_{2} \mathrm{PO} 4\right]+\left[\mathrm{H}_{3} \mathrm{PO} 4\right]=0.1 \mathrm{M}\right),[\mathrm{TvL}] \approx 26 \mathrm{nM}$, and $T \approx 25{ }^{\circ} \mathrm{C}$. For experimental details, see Section 2 . (A) Timedependent changes in the in situ UV/vis/NIR absorption spectrum; (B) time-dependent changes in the in situ EPR spectrum; (C, D) reproducibility test for three separately prepared reaction mixtures with identical composition and a reaction time of $t=24 \mathrm{~h}$; (E) in situ Raman spectrum of the reaction mixture for $t=24 \mathrm{~h}$; (F) HPLC analysis of the reaction mixture after $t=24 \mathrm{~h}$; (G) test of inkjet-printability.

polyelectrolyte or SDBS micelles. In the case of the micelles, the reaction is much slower than with the other templates. In the presence of SPS polyelectrolyte, the oxidation and oligomerization of PADPA are initially rapid, but the UV/ vis/NIR spectrum then becomes unstable and exhibits a broad peak and a decrease of absorbance at around $1000 \mathrm{~nm}$. We conclude that vesicle template systems, like SDBS/DA (1:1) and AOT, are superior in producing PANI-ES-type materials with the desired stable properties. Especially, AOT vesicles foster formation of desired PANI-ES-type products with excellent reproducibility. 
Products obtained with SDBS micelles and the SPS polyelectrolyte show extremely broad EPR signals, indicating poor uniformity of radical centers. Complementary in situ Raman spectroscopy measurements are in good agreement with the UV/vis/NIR and EPR measurements. PANI-ES-type products in stable suspensions can be obtained as dominant products with all four investigated templates under carefully specified reaction conditions. Furthermore, all suspensions are inkjet-printable. However, the choice of the template, especially regarding its shape and size, affects kinetics and product quality. SDBS micelles are least attractive, whereas the SPS polyelectrolyte can compete with vesicles in kinetics but not with product properties. If a high content of the conducting, ordinary PANI-ES polaron form in the products is to be achieved, AOT vesicles are the templates of choice.

\section{ASSOCIATED CONTENT}

\section{S Supporting Information}

The Supporting Information is available free of charge on the ACS Publications website at DOI: 10.1021/acsomega.8b03441.

Details of the preparation of the reaction mixtures, cryoTEM images of a SDBS micellar solution and of a solution of SPS polyelectrolyte, details on the determination of the optimal reaction conditions, in situ Raman spectra recorded during the reaction, chemical structures of the main reaction products identified by HPLC analysis, and HPLC analysis of the extracted and reduced products during the reaction (PDF)

\section{AUTHOR INFORMATION}

\section{Corresponding Author}

*E-mail: peter.walde@mat.ethz.ch.

\section{ORCID $\odot$}

Peter Walde: 0000-0002-0827-0545

\section{Notes}

The authors declare no competing financial interest.

\section{ACKNOWLEDGMENTS}

Fellowships given to K.K. (National Institute of Technology, Faculty Research Abroad Program, Japan) and T.F. (TOBITATE! Young ambassador program from The Japan PublicPrivate Partnership Student Study Abroad Program) for their stay at ETH are highly appreciated. The work was also part of two projects for which financial support was provided by the Swiss National Science Foundation (200020 150254 and IZ73Z0 152457; P.W., S.S.-L., G.Ć.-M., D.B.-B., and A.J.L.) and by the Ministry of Education, Science and Technological Development of Serbia (project OI172043 A.J.L, D.B.-B., and G.C.-M.). We like to thank the technical support for the cryoTEM measurements at the PSI EM facility.

\section{ABBREVIATIONS}

AOT, aerosol AT, sodium bis(2-ethylhexyl)sulfosuccinate; $\mathrm{cmc}$, critical concentration for micelle formation; cryo-TEM, cryogenic transmission electron microscopy; cvc, critical concentration for vesicle formation; DA, decanoic acid; DLS, dynamic light scattering; EPR, electron paramagnetic resonance; HPLC, high-performance liquid chromatography; MS, mass spectrometry; MTBE, tert-butyl methyl ether; PADPA, $p$ aminodiphenylamine; PANI-ES, emeraldine salt form of polyaniline; RT, room temperature; SDBS, sodium dodecylbenzenesulfonate; SPS, sulfonated polystyrene; TvL, Trametes versicolor laccase; UV/vis/NIR, ultraviolet/visible/near-infrared

\section{REFERENCES}

(1) Samuelson, L. A.; Anagnostopoulos, A.; Alva, K. S.; Kumar, J.; Tripathy, S. K. Biologically Derived Conducting and Water Soluble Polyaniline. Macromolecules 1998, 31, 4376-4378.

(2) Liu, W.; Kumar, J.; Tripathy, S.; Senecal, K. J.; Samuelson, L. Enzymatically Synthesized Conducting Polyaniline. J. Am. Chem. Soc. 1999, 121, 71-78.

(3) Liu, W.; Cholli, A. L.; Nagarajan, R.; Kumar, J.; Tripathy, S.; Bruno, F. F.; Samuelson, L. The Role of Template in the Enzymatic Synthesis of Conducting Polyaniline. J. Am. Chem. Soc. 1999, 121, $11345-11355$.

(4) Liu, W.; Kumar, J.; Tripathy, S.; Samuelson, L. A. Enzymatic Synthesis of Conducting Polyaniline in Micelle Solutions. Langmuir 2002, 18, 9696-9704.

(5) Sakharov, I. Y.; Vorobiev, A. C.; Leon, J. J. C. Synthesis of polyelectrolyte complexes of polyaniline and sulfonated polystyrene by palm tree peroxidase. Enzyme Microb. Technol. 2003, 33, 661-667.

(6) Streltsov, A. V.; Morozova, O. V.; Arkharova, N. A.; Klechkovskaya, V. V.; Staroverova, I. N.; Shumakovich, G. P.; Yaropolov, A. I. Synthesis and Characterization of Conducting Polyaniline Prepared by Laccase-Catalyzed Method in Sodium Dodecylbenzenesulfonate Micellar Solutions. J. Appl. Polym. Sci. 2009, 114, 928-934.

(7) Caramyshev, A. V.; Evtushenko, E. G.; Ivanov, V. F.; Barceló, A. R.; Roig, M. G.; Shnyrov, V. L.; van Huystee, R. B.; Kurochkin, I. N.; Vorobiev, A. K.; Sakharov, I. Y. Synthesis of Conducting Polyelectrolyte Complexes of Polyaniline and Poly(2-acrylamido-3methyl-1-propanesulfonic acid) Catalyzed by $\mathrm{pH}$-Stable Palm Tree Peroxiodase. Biomacromolecules 2005, 6, 1360-1366.

(8) Shumakovich, G.; Streltsov, A.; Gorshina, E.; Rusinova, T.; Kurova, V.; Vasil'eva, I.; Otrokhov, G.; Morozova, O.; Yaropolov, A. Laccase-catalyzed oxidative polymerization of aniline dimer (Nphenyl-1,4-phenylenediamine) in aqueous micellar solution of sodium dodecylbenzenesulfonate. J. Mol. Catal. B: Enzym. 2011, 69, 83-88.

(9) Nabid, M. R.; Entezami, A. A. Comparative study on the enzymatic polymerization of $\mathrm{N}$-substituted aniline derivatives. Polym. Adv. Technol. 2005, 16, 305-309.

(10) Kim, B.-K.; Kim, Y. H.; Won, K.; Chang, H.; Choi, Y.; Kong, K.-j.; Rhyu, B. W.; Kim, J.-J.; Lee, J.-O. Electrical properties of polyaniline nanofiber synthesized with biocatalyst. Nanotechnology 2005, 16, 1177-1181.

(11) Xu, P.; Singh, A.; Kaplan, D. L. Enzymatic Catalysis in the Synthesis of Polyanilines and Derivatives of Polyanilines. Adv. Polym. Sci. 2006, 194, 69-94.

(12) Rumbau, V.; Pomposo, J. A.; Alduncin, J. A.; Grande, H.; Mecerreyes, D.; Ochoteco, E. A new bifunctional template for the enzymatic synthesis of conducting polyaniline. Enzyme Microb. Technol. 2007, 40, 1412-1421.

(13) Guo, Z.; Rüegger, H.; Kissner, R.; Ishikawa, T.; Willeke, M.; Walde, P. Vesicles as Soft Templates for the Enzymatic Polymerization of Aniline. Langmuir 2009, 25, 11390-11405.

(14) Guo, Z.; Hauser, N.; Moreno, A.; Ishikawa, T.; Walde, P. AOT vesicles as templates for the horseradish peroxidase-triggered polymerization of aniline. Soft Matter 2011, 7, 180-193.

(15) Walde, P.; Guo, Z. Enzyme-catalyzed chemical structurecontrolling template polymerization. Soft Matter 2011, 7, 316-331.

(16) Junker, K.; Zandomeneghi, G.; Guo, Z.; Kissner, R.; Ishikawa, T.; Kohlbrecher, J.; Walde, P. Mechanistic aspects of the horseradish peroxidase-catalysed polymerisation of aniline in the presence of AOT vesicles as templates. RSC Adv. 2012, 2, 6478-6495.

(17) Junker, K.; Kissner, R.; Rakvin, B.; Guo, Z.; Willeke, M.; Busato, S.; Weber, T.; Walde, P. The use of Trametes versicolor laccase 
for the polymerization of aniline in the presence of vesicles as templates. Enzyme Microb. Technol. 2014, 55, 72-84.

(18) Rakvin, B.; Carić, D.; Andreis, M.; Junker, K.; Walde, P. EPR Study of Polyaniline Synthesized Enzymatically in the Presence of Submicrometer-Sized AOT Vesicles. J. Phys. Chem. B 2014, 118, 2205-2213.

(19) Junker, K.; Luginbühl, S.; Schüttel, M.; Bertschi, L.; Kissner, R.; Schuler, L. D.; Rakvin, B.; Walde, P. Efficient Polymerization of the Aniline Dimer $p$-Aminodiphenylamine (PADPA) with Trametes versicolor Laccase $/ \mathrm{O}_{2}$ as Catalyst and Oxidant and AOT Vesicles as Templaes. ACS Catal. 2014, 4, 3421-3434.

(20) Janošević Ležaić, A.; Luginbühl, S.; Bajuk-Bogdanović, D.; Pašti, I.; Kissner, R.; Rakvin, B.; Walde, P.; Ciríc-Marjanović, G. Insight into the template effect of vesicles on the laccase-catalyzed oligomerization of $\mathrm{N}$-phenyl-1,4-phenylenediamine from Raman spectroscopy and cyclic voltammetry measurements. Sci. Rep. 2016, 6, No. 30724

(21) Luginbühl, S.; Bertschi, L.; Willeke, M.; Schuler, L. D.; Walde, P. How Anionic Vesicles Steer the Oligomerization of Enzymatically Oxidized $p$-Aminodiphenylamine (PADPA) toward a Polyaniline Emeraldine Salt (PANI-ES)-Type Product. Langmuir 2016, 32, 9765-9779.

(22) Kashima, K.; Fujisaki, T.; Serrano-Luginbühl, S.; Khaydarov, A.; Kissner, R.; Janošević Ležaić, A.; Bajuk-Bogdanović, D.; ĆirićMarjanović, G.; Schuler, L. D.; Walde, P. How experimental details matter. The case of a laccase-catalysed oligomerization reaction. RSC Adv. 2018, 8, 33229-33242.

(23) Luginbühl, S.; Milojević-Rakić, M.; Junker, K.; BajukBogdanović, D.; Pašti, I.; Kissner, R.; Cirićc-Marjanović, G.; Walde, $P$. The influence of anionic vesicles on the oligomerization of $p$ aminodiphenylamine catalyzed by horseradish peroxidase and hydrogen peroxide. Synth. Met. 2017, 226, 89-103.

(24) Zhang, Y.; Serrano-Luginbühl, S.; Kissner, R.; Milojević-Rakić, M.; Bajuk-Bogdanović, D.; Ciríc-Marjanović, G.; Wang, Q.; Walde, P. Enzymatic Synthesis of Highly Electroactive Oligoanilines from a $p$ Aminodiphenylamine/Aniline Mixture with Anionic Vesicles as Templates. Langmuir 2018, 34, 9153-9166.

(25) Cruz-Silva, R.; Roman, P.; Romero, J. Enzymatic Synthesis of Polyaniline and Other Electrically Conductive Polymers. In Biocatalysis in Polymer Chemistry; Loos, K., Ed.; Wiley-VCH: Weinheim, 2011; pp 187-210.

(26) Zou, F.; Xue, L.; Yu, X.; Li, Y.; Zhao, Y.; Lu, L.; Huang, X.; Qu, Y. One step biosynthesis of chiral, conducting and water soluble polyaniline in AOT micellar solution. Colloids Surf., A 2013, 429, 3843.

(27) de Salas, F.; Pardo, I.; Salavagione, H. J.; Aza, P.; Amougi, E.; Vind, J.; Martínez, A. T.; Camarero, S. Advanced Synthesis of Conductive Polyaniline Using Laccase as Biocatalyst. Plos One 2016, 11, No. e0164958.

(28) Zhang, Y.; Dong, A.; Fan, X.; Wang, Q.; Zhang, Y.; Yu, Y.; Cavaco-Paulo, A. Laccase-catalyzed synthesis of conducting polyaniline-lignosulfonate composite. J. Appl. Polym. Sci. 2016, No. 42941.

(29) Zhang, Y.; Wang, Q.; Fan, X. Laccase-catalyzed Polymerization of Aniline with Different Soft Templates. Polymer 2018, 42, 175-184.

(30) Cirić-Marjanovic, G. Recent advances in polyaniline research: Polymerization mechanisms, structural aspects, properties and applications. Synth. Met. 2013, 177, 1-47.

(31) Bocchini, S.; Chiolerio, A.; Porro, S.; Accardo, D.; Garino, N.; Bejtka, K.; Perrone, D.; Pirri, C. F. Synthesis of polyaniline-based inks, doping thereof and test device printing towards electronic applications. J. Mater. Chem. C 2013, 1, 5101-5109.

(32) Crowley, K.; Smyth, M. R.; Killard, A. J.; Morrin, A. Printing polyaniline for sensor applications. Chem. Pap. 2013, 67, 771-780.

(33) Stejskal, J.; Trchová, M.; Bober, P.; Humpolíček, P.; Kašpárková, V.; Sapurina, I.; Shishov, M. A.; Varga, M. Conducting Polymers: Polyaniline. Encyclopedia of Polymer Science and Technology, 4th ed.; John Wiley \& Sons: Chichester, 2015.

(34) Kašpárková, V.; Humpolíček, P.; Capáková, Z.; Bober, P.; Stejskal, J.; Trchová, M.; Rejmontová, P.; Junkar, I.; Lehocký, M.;
Mozetič, M. Cell-compatible conducting polyaniline films prepared in colloidal dispersion mode. Colloids Surf., B 2017, 157, 309-316.

(35) Qazi, T. H.; Rai, R.; Boccaccini, A. R. Tissue engineering of electrically responsive tissues using polyaniline based polymers: A review. Biomaterials 2014, 35, 9068-9086.

(36) Nezakati, T.; Seifalian, A.; Tan, A.; Seifalian, A. M. Conductive Polymers: Opportunities and Challenges in Biomedical Applications. Chem. Rev. 2018, 118, 6766-6843.

(37) Wessling, B. Conductive Polymers as Organic Nanomaterials. In Handbook of Nanostructured Materials and Nanotechnology; Nalwa, H. S., Ed.; Academic, Press, 2000; pp 501-575.

(38) Ćirić-Marjanović, G.; Trchová, M.; Stejskal, J. The chemical oxidative polymerization of aniline in water: Raman Spectroscopy. J. Raman Spectrosc. 2008, 39, 1375-1387.

(39) Roy, S.; Fortier, J. M.; Nagarajan, R.; Tripathy, S.; Kumar, J.; Samuelson, L. A.; Bruno, F. F. Biomimetic Synthesis of a Water Soluble Conducting Molecular Complex of Polyaniline and Lignosulfonate. Biomacromolecules 2002, 3, 937-941.

(40) Li, L.; Liang, K.; Hua, Z.; Zou, Z.; Chen, K.; Wang, W. A green route to water-soluble polyaniline for photothermal therapy catalyzed by iron phosphates peroxidase mimic. Polym. Chem. 2015, 6, 22902296.

(41) Tan, Y. Y. The Synthesis of Polymers by Template Polymerization. Prog. Polym. Sci. 1994, 19, 561-588.

(42) Połowiński, S. Template polymerisation and co-polymeristation. Prog. Polym. Sci. 2002, 27, 537-577.

(43) Kim, Y.-J.; Uyama, H.; Kobayashi, S. Regioselective Synthesis of Poly(phenylene) as a Complex with Poly(ethylene glycol) by Template Polymerization of Phenol in Water. Macromolecules 2003, 36, 5058-5060.

(44) Kim, Y.-J.; Shibata, K.; Uyama, H.; Kobayashi, S. Synthesis of ultrahigh molecular weight phenolic polymers by enzymatic polymerization in the presence of amphiphilic triblock copolymer in water. Polymer 2008, 49, 4791-4795.

(45) Peng, Y.; Liu, H.; Zhang, X.; Li, Y.; Liu, S. CNT Templated Regioselective Enzymatic Polymerization of Phenol in Water and Modification of Surface of MWNT Thereby. J. Polym. Sci., Part A: Polym. Chem. 2009, 47, 1627-1635.

(46) Lo, P. K.; Sleiman, H. F. Nucleobase-Templated Polymerization: Copying the Chain Length and Polydispersity of Living Polymers into Conjugated Polymers. J. Am. Chem. Soc. 2009, 131, 4182-4183.

(47) Badi, N.; Lutz, J.-F. Sequence control in polymer synthesis. Chem. Soc. Rev. 2009, 38, 3383-3390.

(48) McHale, R.; Patterson, J. P.; Zetterlund, P. B.; O’Reilly, R. K. Biomimetic radical polymerization via cooperative assembly of segregating templates. Nat. Chem. 2012, 4, 491-497.

(49) ten Brummelhuis, N. Controlling monomer-sequence using supramolecular templates. Polym. Chem. 2015, 6, 654-667.

(50) Tardy, A.; Bhullar, K.; Lim, D. Q.; Thickett, S. C.; Zetterlund, P. B. Revised Insigths into Templating Radical Polymerization within Nanoreactors. J. Polym. Sci., Part A: Polym. Chem. 2017, 55, 15901600.

(51) Shulevich, Y.; Dukhanina, E.; Navrotskii, A.; Novakov, I. Polymerization of trimethylmethacryloyloxyethylammonium methyl sulfate in surfactant micellar solution of sodium alkyl sulfates and properties of the resultant polyelectrolytes. Colloid Polym. Sci. 2018, 296, 871-881.

(52) Li, M.; Zellermann, E.; Schmuck, C. Formation of Polymeric Particles by Direct Polymerization on the Surface of a Supramolecular Template. Chem. - Eur. J. 2018, 24, 9061-9065.

(53) Rusli, W.; Jackson, A. W.; van Herk, A. A Roadmap towards Successful Nanocapsule Synthesis via Vesicle Templated RAFT-Based Emulsion Polymerization. Polymers 2018, 10, 774.

(54) Wang, Y.; Tran, H. D.; Liao, L.; Duan, X.; Kaner, R. B. Nanoscale Morphology, Dimensional Control, and Electrical Properties of Oligoanilines. J. Am. Chem. Soc. 2010, 132, 10365-10373.

(55) Xia, Y.; Wiesinger, J. M.; MacDiarmid, A. G.; Epstein, A. J. Camphorsulfonic Acid Fully Doped Polyaniline Salt: Conformations 
in Different Solvents Studied by an Ultraviolet/Visible/Near-Infrared Spectroscopic Method. Chem. Mater. 1995, 7, 443-445.

(56) Tarver, J.; Loo, Y.-L. Polyanilines. In Conjugated Polymers: A Practical Guide to Synthesis; Müllen, K., Reynolds, J. R., Masuda, T., Eds.; The Royal Society of Chemistry, 2014; Chapter 12, pp 248264.

(57) do Nascimento, G. M.; de Souza, M. A. Spectroscopy of Nanostructured Conductive Polymers. In Nanostructured Conductive Polymers; Eftekhari, A., Ed.; John Wiley \& Sons: Chichester, 2015; pp 341-373.

(58) Dmitrieva, E.; Dunsch, L. How Linear is "Linear" Polyaniline? J.

Phys. Chem. B 2011, 115, 6401-6411.

(59) Bláha, M.; Zedník, J.; Vohlídal, J. Self-doping of polyaniline prepared with the $\mathrm{FeCl}_{3} / \mathrm{H}_{2} \mathrm{O}_{2}$ system and the origin of the Raman band of emeraldine salt at around $1375 \mathrm{~cm}^{-1}$. Polym. Int. 2015, 64, 1801-1807.

(60) Kulikov, A. V.; Bogatyrenko, V. R.; Belonogova, O. V.; Fokeeva, L. S.; Lebedev, A. V.; Echmaeva, T. A.; Shunina, I. G. ESR study of mechanism of polyaniline conductivity. Russ. Chem. Bull. 2002, 51, 2216-2223.

(61) Krinichnyi, V. I.; Roth, H.-K.; Schrödner, M.; Wessling, B. EPR study of polyaniline highly doped by $p$-toluenesulfonic acid. Polymer 2006, 47, 7460-7468.

(62) Hait, S. K.; Majhi, P. R.; Blume, A.; Moulik, S. P. A Critical Assessment of Micellization of Sodium Dodecyl Benzene Sulfonate (SDBS) and Its Interaction with Poly(vinyl pyrrolidone) and Hydrophobically Modified Polymers, JR 400 and LM 200. J. Phys. Chem. B 2003, 107, 3650-3658.

(63) Ma, J. G.; Boyd, B. J.; Drummond, C. J. Positional Isomers of Linear Sodium Dodecyl Benzene Sulfonate: Solubility, Self-Assembly, and Air/Water Interfacial Activity. Langmuir 2006, 22, 8646-8654.

(64) Essafi, W.; Lafuma, F.; Williams, C. E. Effect of Solvent Quality on the Behaviour of Highly Charged Polyelectrolytes. J. Phys. II 1995, 5, 1269-1275.

(65) Baigl, D.; Seery, T. A. P.; Williams, C. E. Preparation and Characterization of Hydrosoluble, Partially Charged Poly(styrenesulfonate)s of Various Controlled Charge Fractions and Chain Lengths. Macromolecules 2002, 35, 2318-2326.

(66) Coughlin, J. E.; Reisch, A.; Markarian, M. Z.; Schlenoff, J. B. Sulfonation of Polystyrene: Toward the "Ideal" Polyelectrolyte. J. Polym. Sci., Part A: Polym. Chem. 2013, 51, 2416-2424.

(67) Iwasaki, F.; Luginbühl, S.; Suga, K.; Walde, P.; Umakoshi, H. Fluorescent Probe Study of AOT Vesicle Membranes and Their Alteration upon Addition of Aniline or the Aniline Dimer pAminodiphenylamine (PADPA). Langmuir 2017, 33, 1984-1994.

(68) Chakraborty, S.; Chakraborty, A.; Ali, M.; Saha, S. K. Surface and Bulk Properties of Dodecylbenzenesulphonate in Aqueous Medium: Role of the Nature of Counterions. J. Dispersion Sci. Technol. 2010, 31, 209-215.

(69) Zhang, J.; Qiu, Y.; Yu, D-Y. Critical Micelle Concentration Determination of Sodium Dodecyl Benzene Sulfonate by Synchronous Fluorescence Spectrometry. Chin. J. Appl. Chem. 2009, 26, $1480-1483$.

(70) Yu, D.; Huang, F.; Xu, H. Determination of critical concentrations by synchronous fluorescence spectrometry. Anal. Methods 2012, 4, 47-49.

(71) Geng, J.; Johnson, B. F. G.; Wheatley, A. E. H.; Luo, J. K. Spectroscopic route to monitoring individual surfactant ions and micelles in aqueous solution: A case study. Cent. Eur. J. Chem. 2014, 12, 307-311.

(72) Sood, A. K.; Aggarwal, M. Evaluation of micellar properties of sodium dodecylbenzene sulphonate in the presence of some salts. $J$. Chem. Sci. 2018, 130, 39.

(73) Hope, M. J.; Nayar, R.; Mayer, L. D.; Cullis, P. R. Reduction of Liposome Size and Preparation of Unilamellar Vesicles by Extrusion Techniques. In Liposome Technology, 2nd ed.; Gregoriadis, G., Ed.; CRC Press: Boca Raton, FL, 1993; Vol. I, pp 123-139.
(74) Namani, T.; Walde, P. From Decanoate Micelles to Decanoic Acid/Dodecylbenzensulfonate Vesicles. Langmuir 2005, 21, 62106219.

(75) Isabettini, S.; Massabni, S.; Hodzic, A.; Durovic, D.; Kohlbrecher, J.; Ishikawa, T.; Fischer, P.; Windhab, E. J.; Walde, P.; Kuster, S. Molecular engineering of lanthanide ion chelating phospholipids generating assemblies with a switched magnetic susceptibility-. PhysChem ChemPhys 2017, 19, 20991-21002.

(76) Förster, S.; Schmidt, M.; Antonietti, M. Static and dynamic light scattering by aqueous polyelectrolyte solutions: effect of molecular weight, charge density and added salt. Polymer 1990, 31, 781-792.

(77) Zhang, Y.; Douglas, J. F.; Ermi, B. D.; Amis, E. J. Influence of counterion valency on the scattering properties of highly charged polyelectrolyte solutions. J. Chem. Phys. 2001, 114, 3299-3313.

(78) Cong, R.; Temyanko, E.; Russo, P. S.; Edwin, N.; Uppu, R. M. Dynamics of Poly(styrenesulfonate) Sodium Salt in Aqueous Solution. Macromolecules 2006, 39, 731-739.

(79) Serrano-Luginbühl, S.; Ruiz-Mirazo, K.; Ostaszewski, R.; Gallou, F.; Walde, P. Soft and dispersed interface-rich aqueous systems that promote and guide chemical reactions. Nat. Rev. Chem. 2018, 2, 306-327.

(80) Cirić-Marjanović, G.; Trchová, M.; Konyushenko, E. N.; Holler, P.; Stejskal, J. Chemical oxidative polymerization of aminodiphenylamines. J. Phys. Chem. B 2008, 112, 6976-6987. 